\title{
RECORRIDO DEL CONCEPTO DE GÉNERO EN LA HISTORIA DEL PSICOANÁLISIS Y SUS IMPLICACIONES CLÍNICAS
}

\author{
Concepció Garriga i Setó \\ Col/legi Oficial de Psicòlegs de Catalunya
}

\begin{abstract}
RESUMEN: En la primera parte de este trabajo se muestran los efectos implícitos de no disponer de teoría respecto al género; de la negación del trauma sexual infantil; y de la ignorancia de la iatrogenia que suponía la violación de límites dentro del espacio analítico (el incesto simbólico). A continuación, se deconstruye la participación de la teoría psicosexual en la institución de la dominación simbólica dentro del psicoanálisis, siguiendo a Bourdieu (1998). Luego, de la mano de Corbett (2009), se parte del "Caso Juanito" (en su centenario) para mostrar como el psicoanálisis "normativiza" acerca de la masculinidad. Se detiene en las aportaciones de Benjamin (1988), Dio Bleichmar (1997), Levinton (2000) y Laplanche (2007). Y, en una segunda parte, basándose en Butler (2004), se muestra la poca consistencia del trabajo de Money (1955) sobre el que se apoyaba todo el edificio conceptual acerca del género y la sexualidad construido hasta el momento. La teoría queer lo acaba de sacudir. Termina viendo la dirección que está tomando el género en el el siglo XXI con las contribuciones de Chodorow (1999, 2005), Dimen (2002, 2003), Goldner (2002, 2003), Harris (2005) y Layton (2004).
\end{abstract}

Palabras clave: Género, sexualidad, clase, dominación simbólica, teoría queer.

VICISSITUDES OF THE CONCEPT OF GENDER WITHIN PSYCHOANALYSIS. FIRST PART

ABSTRACT: In the first part of this work, the implicit effects of not having a theory with respect to gender; of the negation of the sexual child trauma; and of the ignorance of the iatrogenia, that boundary violation in the analytical space (the symbolic incest) entails are shown. Next, the participation of the 
psychosexual theory in the institution of the symbolic domination in psychoanalysis is deconstructed, following Bourdieu (1998). Afterwards, assisted by Corbett (2009), through "Little Hans" it is shown how psychoanalysis "normatises" about masculinity. It stops at Benjamin's (1988), Dio Bleichmar's (1997), Levinton's (2000) and Laplanche's (2007) contributions. And, in a second part, based on Butler (2004), it is shown the little consistency of the work of Money (1955) on which all the conceptual building about gender and sexuality constructed up to then was leaning. Queer theory finished the job. It ends up with the view of the direction that gender is taken in the 21 st century with the contributions of Chodorow (1999, 2005), Dimen (2002, 2003), Goldner (2002, 2003), Harris (2005) and Layton (2004).

Keywords: Gender, sexuality, class, symbolic domination, Queer theory.

\section{El punto de partida}

El psicoanálisis surgió a finales del XIX, principios del siglo XX, por lo tanto se nutrió de la cultura y de las creencias imperantes en la época. A lo largo del siglo XX ha tenido que ir evolucionando a tenor de los cambios culturales que se iban produciendo, tarea que ha corrido a cargo de sus corrientes más abiertas, como el Psicoanálisis Relacional, que a finales de siglo y de la mano del malogrado Stephen Mitchel y de Jessica Benjamin (sus más eminentes promotores) recogieron y reformularon el pensamiento de la época, alentados por revistas como Psychoanalytic Dialogues y ediciones como The Analytic Press, que sacudieron los cimientos sobre los que se fundamentaba el psicoanálisis tradicional. Este nuevo pensamiento recogía en su seno los aportes de la que ha sido, para el mundo occidental, la mayor y más trascendente de las revoluciones pacíficas que hayan tenido lugar después de la implantación de las democracias: el reconocimiento y la práctica, aun minoritaria e imperfecta, de los derechos individuales de las mujeres, que tuvo lugar a partir de las que se ha dado en Ilamar sucesivas olas del feminismo.

La primera ola, la que se libró para que las mujeres obtuvieran el derecho al voto; la segunda ola, promovía la igualdad de oportunidades, reconocía la validez del deseo sexual de las mujeres y proponía el reconocimiento de las diferencias de clase y de raza entre ellas. Las pioneras dentro del entorno "psi" fueron Nancy Chodorow (1978) ${ }^{1}$, Betty Friedan $(1963)^{2}$, Kate Millet (1969) ${ }^{3}$,

1. Chodorow, N., The Reproduction of Mothering. Berkeley: University of California Press, 1978. (Versión en castellano: El ejercicio de la maternidad. Barcelona: Gedisa 1984).

2. Friedan, B., The Feminine Mystique. New York: W. W. Norton, 1963. (Versión en castellano: La Mistica de la Feminidad. Gijon: Júcar, 1974).

3. Millet, K., Sexual Politics. New York: Doubleday, 1969. 
Ethel Person $(1980)^{4}$, Adrienne Rich $(1976)^{5} \ldots$ en USA; y Simone de Beauvoir $(1952)^{6}$, Juliet Mitchel $(1974)^{7}$, Susie Orbach $(1986)^{8}$, Eichenbaum y Orbach $\left(1983 a^{9}, 1983 b^{10}\right)$, Dio Bleichmar $(1985)^{11} \ldots$ en Europa (lista muy limitada); proceso que se ha ido completando con el feminismo de la tercera ola, que ha tenido sus teóricas "psi" (Bejamin, 1988 ${ }^{12}$, 1995 ${ }^{13}$, 1998 ${ }^{14}$; Chodorow, 1994 ${ }^{15}$, 199916, 200517; Dimen \& Goldner, 2002 ${ }^{18}$; Dimen, 2003 ${ }^{19}$; Gilligan, $1982^{20}$; Goldner, 200321; Harris, 200522; Layton, 199823) y a las que se han sumado las aportaciones de la teoría queer (Butler, 199324; Corbett, 2002 ${ }^{25}$ ) con el reconocimiento de que ni el género ni la sexualidad son sistemas duales excluyentes, sino que el género y el deseo sexual son flexibles, y flotan libremente dando lugar a múltiples posiciones de la identidad; que comprenden el cuerpo como expresión personal, la pluralidad de géneros, y los malabarismos entre carrera,

4. Person, E. S., "Sexuality as the Mainstay of Identity", 1980 en The Sexual Century. New Haven and London: Yale University Press, 1999.

5. Rich, A., Of Woman Born: Motherhoods as Experience and Institution. New York: W. W. Norton, 1976. (Versión en castellano: Nacemos de Mujer. Madrid: Cátedra, 1996).

6. de Beauvoir, S. (1952), Le Deuxième Sexe. Paris: Gallimard. (Traducción castellano: El segundo Sexo. Buenos Aires: Siglo XX, 1970).

7. Mitchel, J., Psychoanalysis and Feminism. New York: Pantheon Books, 1974. (Version en castellano: Psicoanálisis y Feminismo. Barcelona: Anagrama, 1982).

8. Orbach, S., Hunger Strike. London \& Boston: Faber and Faber, 1986.

9. Eichenbaum, L. y Orbach, S., Understanding Women. London: Penguin, 1983a.

10. Eichenbaum, L. y Orbach, S., What do women want? London: Penguin, 1983b. (Traducción castellano: ¿Qué quieren las mujeres? Madrid: Revolución).

11. Dio Bleichmar, E., El feminismo espontáneo de la histeria. Madrid: Adotraf, 1985.

12. Benjamin, J., The Bonds of Love. London: Virago Press, 1988. (Traducción castellano: Lazos de amor. Barcelona: Paidós, 1995).

13. Benjamin, J., Like subjects, Love Objects. New Haven \& London: Yale University Press, 1995. (Traducción castellano: Sujetos Iguales: Objetos de Amor. Barcelona: Paidós, 1997).

14. Benjamin, J., The Shadow of the Other. New York \& London: Routledge, 1998.

15. Chodorow, N., Femininities, Masculinities, Sexualities. London: Free Association Books, 1994.

16. Chodorow, N., The Power of Feelings. New Haven \& London: Yale University Press, 1999.

17. Chodorow, N., "Too Late", en Brown, Sh. F., What do Mothers Want? Hillsdale: The Analytic Press, 2005.

18. Dimen, M. y Goldner, V., Gender in Psychoanalytic Space. New York: Other Press, 2002.

19. Dimen, M., Sexuality, Intimacy, Power. Hillsdale: The Analytic Press, 2003.

20. Gilligan, C., In a Different Voice: Psychological Theoria and Women's Development. Cambridge: Harvard University Press, 1984. (Traducción en castellano: La moral y la teoría. Psicología del desarrollo moral femenino. México: Fondo de Cultura Económica, 1985).

21. Goldner, V., "Ironic Gender/Authentic Sex", Studies in Gender and Sexuality, 4 (2), 2003, pp. 113-139.

22. Harris, A., Gender as Soft Assembly. Hillsdale: The Analytic Press, 2005.

23. Layton, L., Who's that girl? Who's that boy? Hillsdale: The Analytic Press, 1998 (Reedición: 2004).

24. Butler, J., Bodies that Matter. New York: Routledge, 1993.

25. Corbett, K., "The mystery of Homosexuality", en Dimen, M. y Goldner, V., Gender in Psychoanalytic Space. New York: Other Press, 2002. 
sexo, maternidad. Actualmente ${ }^{26}$ se postula una cuarta ola del feminismo, la del siglo XXI, que algunas Ilaman espiritual, y otras comunitario, caracterizada por la preocupación por el planeta y todos su seres vivos.

Esta revolución ha sido posible gracias al malestar -o dolor- que sentían las mujeres al darse cuenta del destino que les esperaba por el hecho de tener asignado normativamente un rol de género que las dejaba en franca desventaja para vivir en el mundo: sin recursos económicos, con la responsabilidad exclusiva de la crianza, sin capacidad de decisión respecto a nada que las afectara, ni siquiera respecto a su propio cuerpo; siendo criadas para la sumisión y el abuso sexual. En definitiva, un destino de esclavas físicas y sexuales que sólo daba lugar a psicopatologías de menor o mayor gravedad: narcisismo, histeria, somatizaciones o psicosis, dependiendo de la edad de inicio y de la duración ${ }^{27}$ del maltrato, que, como veremos a continuación, el primer psicoanálisis no solo no fue capaz de resolver, sino que contribuyó a empeorar. A pesar de lo cuál dicha revolución también tuvo lugar dentro de sus mismas filas gracias particularmente a las autoras que nombro en este trabajo.

\section{La teoría de la seducción}

Tal como muestran los y las diversos autores y autoras en que me baso, el psicoanálisis ha tenido un carácter normativo y muchos puntos ciegos. Uno de ellos es paradójicamente uno de los fundamentos del psicoanálisis. Me refiero a las vicisitudes y la retirada de la mal Ilamada teoría de la seducción así como su nueva incorporación a la teoría. Empezaré por aquí para hacer un relato cronológico.

Para este relato me basaré en Intebi $(1998)^{28}$ que remite a "Juicio a la psicoterapia", una obra que Jeffrey Masson (1984) ${ }^{29}$, director custodio de los Archivos Sigmund Freud, escribió justamente para aportar datos respecto a dicha teoría.

Freud empezó siendo el psiquiatra que escuchaba atentamente a sus pacientes mujeres, y se enteraba que en el pasado de todas ellas se escondían terribles y violentos acontecimientos y, fundamentalmente, las creyó. Con "La etiología de la histeria", $1896^{30}$, Freud hizo públicos sus hallazgos sobre la histeria que consistían en episodios reales de seducción sexual acaecidos en

26. Studies in Gender and Sexuality, Vol. 10 (4), 2009.

27. Hay un excelente trabajo de Talarn, A., "El trauma desde la perspectiva de la psicología y del psicoanálisis", de 2004, comunicación personal dentro del II Seminari de Formació Continuada en Psicoanàlisi Relacional Contemporània que dirigían F. Sáinz y R. Riera en BCN.

28. Intebi, I. V., El abuso sexual en las mejores familias. Barcelona: Granica, 1998.

29. Masson, J., The Assault on Truth. Farrar. Straus and Giroux, 1984. Traducido como Juicio a la Psicoterapia. Santiago de Chile: Cuatro Vientos, 1991. Citado en Intebi, I. V., El abuso sexual en las mejores familias. Barcelona: Granica, 1998.

30. Freud, S., "La Etiología de la Histeria" 1986, Obras completas. Madrid: Biblioteca Nueva, 1981, 4ª ed. pp. 299-316. 
la infancia de las pacientes $-y$ provocados por adultos- que se determinan como fuerza traumática. En concreto, dijo "en la base de todo caso de histeria se encuentran una o varias vivencias -reproducibles por el trabajo analítico, aunque el intervalo alcance decenios- de experiencia sexual prematura y pertenecientes a la niñez primera como: estimulación de los genitales, acciones semejantes al coito... en las que deben reconocerse en el análisis aquellos traumas de los cuáles arrancan tanto la reacción histérica, como el desarrollo de síntomas histéricos. Freud además se ocupaba de aportar detalles que apuntalaban esta realidad.

En los 18 casos sin excepción que presentó de histeria halló vivencias sexuales de este tipo en la infancia de sus pacientes. En $1897^{31}$ le escribió a Fliess para decirle que ya no creía en su neurótica teoría de las neurosis. A pesar de ello seguía encontrando y escribiendo de casos en que habían tenido lugar unas situaciones tan espeluznantes que le dijo a Fliess: un nuevo paradigma para el psicoanálisis debería ser “¿Qué te han hecho? ¡Pobre criatura!".

Cuando en $1905^{32}$ escribió los "Tres ensayos" ya no quedaba ni rastro de la teoría de la seducción, y afirmaba que "Ios sucesos traumáticos de la infancia constituyen una defensa para evitar vivenciar plenamente los sucesos de la adolescencia".

Sigue Intebi: "este cambio fue debido a las presiones que recibía de sus seguidores, que temían que sostener la realidad de la seducción frenara el avance de la teoría psicoanalítica". Anna Freud (1981)33 añadió "sostener la teoría de la seducción hubiera significado abandonar el complejo de Edipo", y con él toda la importancia de las fantasías conscientes o inconscientes. De hecho, ella creía que posteriormente no hubiera existido el psicoanálisis. En realidad Freud se desdijo por no quedar aislado y limitado económicamente. Lo que pasó fue que desembarazarse de la dimensión real de los relatos creó un sistema de explicaciones poco consistentes que los psicoanalistas remiten mediante interpretación a los propios deseos incestuosos de las pacientes; a su impulsividad y hostilidad a los padres, creando así un circulo vicioso de retraumatizaciones muy patógeno, causante de iatrogenia.

Dilucidar las consecuencias del hecho de que Freud abandonara la realidad de las escenas de seducción infantiles es crucial para las personas que han sido victimizadas y para las personas que las escuchan. Quizá muchos relatos de abusos sexuales no se desecharían escudándose en las fantasías infantiles y en la capacidad de fabulación de las histéricas.

Intebi (1998) ${ }^{34}$ cita como ejemplo el caso de Rosana, una adolescente de 15 años, hija menor de un matrimonio de clase media. Su madre denunció

31. Correspondencia citada por Masson, J., The assault...

32. Freud, S., "Tres ensayos para una teoría sexual", 1905, Obras..., pp. 1169-1237.

33. Cita de Intebi, I. V., El abuso..., p. 96.

34. Intebi, I. V., El Abuso..., pp. 97-98. 
al Juzgado de Menores que su hija estaba siendo víctima de comportamientos sexuales inadecuados por parte de su padre. El informe psicológico dice: "en relación a las vivencias traumáticas con la sexualidad que se observan en el material no puede afirmarse ni negarse su exclusiva relación con los hechos que se investigan, dado que en esta etapa pueden observarse problemáticas similares respecto a la sexualidad". Recomienda tratamiento psicológico.

Después del sobreseimiento del padre, Rosana fue derivada para tratamiento a un centro especializado en maltrato infantil. Allí relató que el padre maltrataba físicamente a todos los integrantes de la familia, aunque con ella era más indulgente. A la cuarta sesión relató que viendo la tele en el sofá su padre se le subió encima, a caballito, y la empezó a tocar, le abrió la camisa y le metió mano, y varias escenas de este tipo.

A pesar de estas evidencias el padre acusó a la madre de enferma mental, obstaculizó el tratamiento psicoterapéutico de Rosana hasta que ésta lo abandonó, y Rosana siguió viviendo con su padre a pesar de haber expresado sus temores al juez.

Al rechazar la teoría de la seducción Freud abrió una exclusa -o una excusa- que permite a los profesionales evitar el contacto con los intensos sentimientos que genera creer la veracidad del abuso. También fue una manera de no cuestionar el "statu quo" de poder y privilegios de los hombres de la época, y de sus propios seguidores que, como veremos, incurrían en todo tipo de licencias sexuales con sus pacientes y conocidas, a menudo con el beneplácito e incluso con la invitación de Freud, quienes, ignorando, o mejor, negando, los efectos de sus acciones, podían seguir perpetrándolas.

\section{El caso Ernest Jones}

En 1903, en 1906 y en 1907 estaban sucediendo unos hechos en Londres que creo oportuno narrar ${ }^{35}$. En 1903 hicieron dimitir a Jones como médico del Hospital de Niños del Noroeste de Londres por conducta indecente. Después tuvo que aceptar trabajos de menor grado, como el que obtuvo para el London County Council, que consistía en pasar pruebas individuales a criaturas retardadas. El primer día de trabajo ya hubo una queja por parte de un niño, y de tres niñas. Gracias a la denuncia de los padres de una de las niñas a la policía, Jones fue arrestado, acusado de "abuso indecente" y absuelto dos meses después a pesar de que había una prueba irrefutable: un mantel manchado de semen. Apenas 6 meses después obtuvo otro puesto en el Hospital de Enfermedades Nerviosas, del que fue despedido al poco tiempo por inadecuación sexual. Después de esto Jones se acercó al psicoanálisis. En 1908 emigró a

35. El volumen 3, número 4, de 2002 de Studies in Gender and Sexuality está dedicado íntegramente a este caso. En este apartado hago un pequeño resumen del debate: Ernest Jones revisited: A Symposium. 
Toronto, Canada, como psiconalista y allí, una de sus primeras pacientes le amenazó de demandarle por explotación sexual. A su vuelta a Europa, a Viena, en 1912, se incorporó en la sociedad de Freud.

Gabbard \& Lester (1995) ${ }^{36}$, explican que al principio del psicoanálisis hubo muchas violaciones de límites y que el mismo Freud era muy tolerante, e incluso incitador de estas conductas. Así lo hizo con la "destrozada y morfinómana" pareja de Jones, a quien trató y luego animó a que se casara con otro psicoanalista. También sugirió al psicoanalista Fink que se casara con su primera paciente, literalmente, "porqué era rica y así haría contribuciones significativas para el psicoanálisis". En otro trabajo Gabbard (2002) ${ }^{37}$ afirma que por esta época Freud se dio cuenta de que si sus seguidores incurrían en tantas implicaciones sexuales con sus pacientes, destruirían la nueva disciplina, y fue entonces cuando empezó a redactar los diez mandamientos de la técnica analítica. Kerr $(1993)^{38}$, uno de los historiadores del psicoanálisis, señala que la explotación sexual de pacientes era omnipresente.

Kerr reconoce que esta situación sólo ha empezado a cambiar a partir de los 80, particularmente gracias a la presión que han ejercido las mujeres analistas, y al reconocimiento del incesto como factor principal de patología, es decir, después de volver a "corregir" la teoría de la seducción. De aquí ha derivado la noción de que el sexo entre analista y paciente es simbólicamente incestuoso, ergo patógeno.

Kerr termina su narración diciendo que Jones puede ser profundamente despreciable por los abusos cometidos pero que también puede ser profundamente admirable porque durante la época nazi salvó la vida de unos 50 analistas y sus familias.

\section{Respecto a la feminidad en el psicoanálisis clásico}

A pesar de las múltiples contribuciones que se han hecho desde diversos ámbitos, todavía hay mucha investigación en psicoanálisis tradicional que acaba remitiendo, en un círculo cerrado y vicioso, a la palabra de Freud y a sus teorías del desarrollo psicosexual, y que acaba encontrando finalmente la "roca base" (protesta masculina y deseo del pene), de manera que el discurso sobre la sexualidad/identidad femenina acaba siendo más un discurso de cómo la veían estos hombres (Freud, Abraham, Jones,...) y la cultura de principios del siglo XX, que una experiencia de las mujeres, es decir, es una mirada androcéntrica y arcaica. El problema es que hay sociedades psicoanalíticas que

36. Gabbard, G. O. y Lester, M., Boundaries and Boundary Violations in Psychoanalysis. New York: Basic Books, 1995.

37. Gabbard, G. O., "Boundary Violations and the Abuse of Power. Commentary on Paper by Philip Kuhn", Studies in Gender and Sexuality, 2002, 3(4), pp. 379-388.

38. Kerr, J., A Most Dangerous Method: The Story of Jung, Freud and Sabina Spielrein. New York: Knopf, 1993. 
actualmente siguen leyendo acríticamente los textos de Freud, sin cuestionar que esta manera de ver corresponde a un momento histórico impregnado por siglos de tradición judeo-cristiana, y que además ha contribuido a su perpetuación, al dar fundamento, en apariencia natural, a la dominación masculina enraizada en la manera de organizarse las familias, tal como ha demostrado Bourdieu (1998) ${ }^{39}$.

Bourdieu nos muestra que lo que en la historia aparece como natural e inmutable no es más que el producto de un trabajo constante de reproducción. El psicoanálisis es una de las instituciones que ha contribuido a la reproducción de la dominación simbólica. El sistema binario o polar de clasificación: cuerpo/mente, naturaleza/cultura (Benjamin, 1988) ${ }^{40}$ cuando se transforma en esquema de pensamiento y se refiere al binario mujer/hombre, acaba otorgando todo lo que aparece como valioso al hombre, y lo que queda, los elementos primitivos y arcaicos de la vida humana, a la mujer.

Veamos como la institución psicoanalítica transforma la diferencia sexual (de los cuerpos) en desigualdad social, dando la apariencia de natural-biológica. Bem (1993) ${ }^{41}$ explica que a finales del XIX las disciplinas aliadas de la medicina (sexología, psiquiatría y psicología) dieron legitimidad científica al requerimiento cultural de que el sexo del cuerpo casara con el de la mente (entonces no disponían del concepto de género).

Voy a deconstruir los textos de Freud acerca de la sexualidad femenina (que él Ilama desarrollo psicosexual y que hoy entendemos por identidad de género), como ejemplo paradigmático de ejercicio de dominación simbólica, con la ayuda de Bourdieu (1998) ${ }^{42}$. Lo que Freud Ilama desarrollo psicosexual no es otra cosa que la conversión en desigualdad jerárquica de la diferencia sexual arbitraria. Para él la sexualidad -se refiere al género, o al sistema sexogénero- viene determinada por la biología. En su primer escrito, de $1905^{43}$ "La sexualidad infantil", postula que los niños tienen la teoría de que ambos sexos poseen el mismo aparato genital. Afirma que las niñas sucumben a la envidia del pene, que culmina con el deseo de ser un niño. Karen Horney (1924) ${ }^{44}$ ya dijo que, en todo caso, lo que las niñas envidiaban era la situación privilegiada de los niños y de los hombres y no el pene.

En 192445, Freud afirma que la anatomía es el destino, que el clítoris se comporta como un pene, pero que cuando la niña lo compara con uno de

39. Bourdieu, P., La dominación masculina. Barcelona: Ediciones 62, 2000 (original, 1998).

40. Benjamin, J., The Bonds of Love. London: Virago Press, 1988. (Traducción castellano: Lazos de amor. Barcelona: Paidós, 1995).

41. Bem, S. L., The lenses of gender. New Haven and London: Yale University Press, 1993.

42. Bourdieu, P., La dominació...

43. Freud, S., "Tres ensayos...", pp. 1195-1215.

44. Horney, K., "On the genesis of the castration complex in women", Int. J. Psychoanal., 1924,5 , pp. 50-65.

45. Freud, S., "La disolución del complejo de Edipo", 1924, Obras..., pp. 2748-2751. 
verdad siente este hecho como una desventaja y un motivo de inferioridad. Entonces la niña supone que lo perdió por castración, y acepta este hecho como consumado. En el complejo de Edipo la renuncia al pene debe tener una compensación, la niña pasa de la idea de pene a la idea de niño, y que este será un regalo de su padre. En este mismo texto Freud reconoce que su conocimiento del proceso evolutivo de la niña es incompleto e insatisfactorio.

En $1925^{46}$, afirma que la niña se da cuenta de que el pene es muy visible y de grandes proporciones, que lo reconoce como símil de su propio órgano pequeño e inconspicuo, y que desde este mismo momento cae víctima de la envidia fálica. En este texto Freud habla de la masturbación clitoridiana como masculina, y observa que las niñas tienden menos a recorrer a la masturbación que los niños. Lo atribuye a la represión de la sexualidad masculina a fin de que se pueda desarrollar su feminidad. En este texto Freud afirma literalmente: "la divergencia entre el desarrollo sexual masculino y el femenino es una consecuencia comprensible de la diferencia anatómica entre los genitales y de la situación psíquica implícita: equivale a la diferencia entre una castración realizada y una mera amenaza de castración". En un año Freud ha pasado de "la niña supone que lo perdió por castración" (en "La disolución del complejo de Edipo") a creer, él mismo, y a sostener que ha sido castrada realmente. En un año ya no pone la distancia de la creencia "falsa", por tanto a corregir, de los niños y las niñas, sino que ya habla (ipor identificación inconsciente con los niños?) de castración realizada en la niña. Esta es su teoría del sexo único.

Por cierto, lo que sabemos actualmente respecto al sexo único masculino, gracias a los hallazgos de la embriología, es que justamente lo contrario es cierto. En ausencia de andrógenos un embrión, aunque genéticamente sea macho, se desarrollará como hembra. El estado neutro, de reposo o inicial para los mecanismos centrales del sexo, así como los rudimentos de los órganos sexuales y de sus aparatos anexos, son femeninos; es decir, si el flujo de andrógenos es bloqueado, el cerebro femenino retoma el mando. El cerebro humano, embriológicamente hablando, es hembra, y, si en un periodo crítico determinado -la octava semana- recibe el empuje de los andrógenos liberados por el cromosoma " $y$ ", entonces se masculiniza. De la misma manera, el pene resulta de la androgenización del clítoris, de manera que no se puede seguir sosteniendo que el clítoris sea ni embriológica, ni anatómicamente, un órgano masculino ${ }^{47}$.

El regulador cerebral de la sexualidad es el hipotálamo (Tobeña, 1995) ${ }^{48}$. Se han encontrado diferencias anatómicas muy notables en el hipotálamo de hombres y mujeres en el sentido que los hombres tienen el área preóptica mu-

46. Freud, S., "Algunas consecuencias psíquicas de la diferencia sexual anatómica", 1925, Obras..., pp. 2896-2903.

47. Dio Bleichmar, E., La sexualidad femenina, de la niña a la mujer. Barcelona: Paidós, 1997, p. 344.

48. Tobeña, A., El cervell eròtic. Barcelona: La Campana, 1995, p. 30. 
cho más desarrollada que las mujeres, mientras que en las mujeres el mayor es el núcleo ventromedial, estas diferencias lo son tanto en volumen como en número de neuronas. Hay evidencias de que estas áreas regulan el deseo y la conducta sexual de forma dimórfica. También se han encontrado diferencias en estas estructuras entre homosexuales y heterosexuales (LeVay, 1993) ${ }^{49}$.

En $1931^{50}$, Freud afirma que la mujer tiene dos zonas sexuales: la vagina, órgano sexual femenino, y el clítoris, masculino. También afirma que del reconocimiento de la castración pasa a reconocer la superioridad del hombre y su propia inferioridad, y que se revela contra este estado de cosas de tres maneras:

1) apartándose de la sexualidad

2) autoafirmándose en la masculinidad

3) adoptando la actitud femenina normal

Lo que entiende por actitud femenina normal lo encontramos en "La femini-

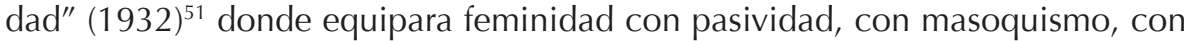
docilidad y con dependencia. Y dice que con el viraje hacia la feminidad el clítoris tiene que ceder total o parcialmente su sensibilidad y con ella su significación a la vagina (¡A las mujeres se les pide un imposible! ¿Qué quiere decir ceder su sensibilidad? Se pueden pasar toda la vida en análisis y frustradas. ¡Cuanta iatrogenia! ¡Es como si a los hombres se les pidiera que deben ceder la sensibilidad de su pene al ano, por ejemplo, por citar zonas erógenas! Toda esta mitología acerca del doble orgasmo se ha prolongado mucho y ha hecho mucho daño a muchas mujeres. Masters y Johnson $(1966)^{52}$ ya mostraron que "desde un punto de vista fisiológico, todos los orgasmos femeninos se atienen a las mismas pautas de respuesta refleja, sea cual fuere la fuente de estimulación sexual: frotación del clítoris, estimulación de los pechos, o el coito" ${ }^{\prime \prime 3}$

En este texto ("Sobre la sexualidad...") Freud Ilega al clímax de la violencia simbólica que está perpetrando, al afirmar: "la consecución de la finalidad biológica ha sido confiada a la agresión del hombre y hecha independiente, en cierta medida, del consentimiento de la mujer" (Creo que es interesante leer este texto como documento histórico de cuál era la teoría que sustentaba una práctica sexual de los hombres absolutamente dominante, sin ningún tipo de inhibición ni cuestionamiento, y que nos muestra, además su carácter normativo. A la vez que describe, prescribe como debe ser: al hombre se le daba legitimidad para la violación, sin más consideraciones). ¡Ah, esto sí, con la finalidad de la reproducción! Porque debe ser a esto a lo que se refiere la finalidad biológica). Un discurso así de descarado lo sostenía unos años después

49. Le Vay, S., The sexual brain. Cambridge: MIT Press, 1993.

50. Freud, S., "Sobre la sexualidad femenina", 1931, Obras..., pp. 3077-3089.

51. Freud, S., "La feminidad", 1932, Obras..., pp. 3164-3177.

52. Masters, W. H. y Johnson, V. E., Human sexual response, Boston: Little Brown, 1966.

53. Masters H. W., Johnson, V. E. y Kolodny, R. C., La sexualidad Humana. 1992, Barcelona: Grijalbo, 1995, p. 89. 
la sección femenina de la Falange Española. Y en la actualidad los talibanes afganos que han instado a Karzai a promulgar una ley que obliga a las mujeres a mantener relaciones sexuales siempre que sus maridos lo requieran.

Masters, Johnson y Kolodny $(1992)^{54}$ lo exponen de una manera bien clara "hasta mitades del siglo XX, muchas personas, entre ellas autoridades médicas, consideraban que la mujer no era capaz de alcanzar un orgasmo. Esta creencia era el reflejo del prejuicio cultural de que el sexo era un acto que el hombre perpetraba para su exclusiva gratificación, teniendo a la mujer como sujeto pasivo. Por espacio de siglos se instó a las mujeres a "cumplir con sus deberes conyugales" prestándose en todo momento a los requerimientos sexuales del marido, a la vez que se les inculcaba la idea de que las mujeres "decentes" no debían complacerse en el amor sexual. Puesto que las muestras de placer físico o tener un orgasmo se consideraba "impropio de una dama", es normal que muchas mujeres no pudieran lograr orgasmos. Se implantó en ellas la idea de que "no podían experimentar placer sexual, y que, si eran capaces de tenerlo, no debían permitírselo".

Volviendo al análisis del discurso de Freud, Chodorow $(1994)^{55}$ nos cuenta que cuando Freud tenía el cáncer operado las psicoanalistas mujeres estaban publicando más deprisa que él, y que esta situación le instigó "La sexualidad femenina". Y añade, lo que él llamaba "feminidad normal" es en realidad "feminidad normativa". Aquello que es la organización psicológica de algunas mujeres se convirtió en el desarrollo femenino en general.

Freud acabó llegando a la conclusión, en 193756, que, "para lo psíquico, la biología hace el papel de fundamento rocoso subyacente. Efectivamente, dice, el repudio de la feminidad no puede ser más que un hecho biológico, una pieza del gran enigma de la sexualidad". (Nunca antes en ningún texto había salido la palabra repudio, y de repente: aquí está, sin sujeto. ¿Quien repudia la feminidad, él mismo, los hombres, las mujeres? ¿De donde sale este repudio? ¿De si mismo? ¿De la cultura?). Queda claro que él mismo queda preso de los efectos que está produciendo. Ha convertido una diferencia biológica en una desigualdad jerárquica: un superior valorizado y una inferior deplorable (abyecta en terminología postmoderna); sistema de polaridad binario excluyente. Con esta operatoria legitima una relación de dominación inscribiéndola en una naturaleza biológica, lo cuál es, en si mismo, una construcción social naturalizada (Bourdieu, 1998) ${ }^{57}$.

El establecimiento de esta estructura de dominación simbólica, sigue Bourdieu, no es gratuito en absoluto, sino todo lo contrario, es el resultado de

54. Masters H. W., Johnson, V. E. y Kolodny, R. C., La sexualidad Humana. 1992, Barcelona: Grijalbo, 1995, p. 80. 1994

55. Chodorow, N., Femininities, Masculinities, Sexualities. London: Free Association Books,

56. Freud, S., "Anàlisis Terminable e Interminable", 1937, Obras..., pp. 3339-3364.

57. Bourdieu, P., La dominació... 
un trabajo ingente colectivo de "educación" y socialización difuso y continuo, que va modificando las representaciones del cuerpo (cerebro incluido) para acabar produciendo el artefacto social que se llama el hombre viril y la mujer femenina (los estereotipos de género). Como acabamos de ver, el psicoanálisis ha contribuido a este trabajo de reproducción del patriarcado y el androcentrismo, como no podía de otra manera, puesto que era la cultura que se había estado generando y reproduciendo desde hacía unos 5000 años, que posteriormente se plasmó en la filosofía Aristotélica en la cual, según Celia Amoros (1985) ${ }^{58}$ encontramos una verdadera "operación patriarcal de legitimación genealógica de la historia de la filosofía", operación reforzada, algunos siglos más tarde, por la religión judeocristiana monoteísta que instauró un dios único, una trinidad masculina (el padre, el hijo y el espíritu santo) y dos figuras femeninas dramáticas para el lugar de la mujer: Eva, la desobediente, la transgresora y la pecadora, y María, la sumisa y la abnegada, además de un mito de creación del mundo, ilógicamente también masculino (Dios crea a Adán y de su costilla... etc.). En pocas palabras, desde Aristóteles hasta Lacan se construye una filosofía occidental hondamente misógina.

Para abundar en el tema, la historiadora Almudena Hernando (2000) ${ }^{59}$, explica que la falta de subjetividad individualizada de las mujeres responde a un plan ejecutado con toda precisión desde el siglo XII. En aquella época la sociedad se individualizaba para hacer frente a la vida cotidiana. Con el fin de frenar el proceso de individualización de las mujeres inherente a las transformaciones que estaban teniendo lugar, intervino la iglesia. Se empezó a venerar a la Virgen Maria -el ideal de mujer no individualizada, la madre generosa que renuncia a los deseos personales, incluido el sexual. También se reforzó el mito de origen: que el mundo perdió la condición de paraíso cuando la mujer (Eva) se atrevió a acercarse al árbol del conocimiento; idealizando la figura desindividualizada como modelo de mujer (el acceso de las mujeres al conocimiento -escolarización, lectura...- es uno de los elementos fundamentales para su individuación-subjetivación $)^{60}$. Desde este punto de vista no es extraño que el pecado original sea acercarse al conocimiento. A partir del siglo XII los hombres empezaron a legislar para excluir a las mujeres de todas partes. Si se querían individualizar la única salida que les quedaba era meterse en un con-

58. Amorós, C., Hacia una crítica de la razón patriarcal. Barcelona: Anthropos, 1985, (2a ed. 1991).

59. Hernando, A., "Factores estructurales asociados a la identidad de género femenina. La no-inocencia de una construcción socio-cultural", en Hernando, A. (coord.), La construcción de la subjetividad femenina. Madrid: Instituto de Investigaciones Feministas. Universidad Complutense de Madrid, 2000. pp. 101-142.

60. Este verano, en una travesía por los Pirineos, en el que íbamos cuatro mujeres y tres hombres de alrededor de 50, salió en la conversación que ninguna de las familias de las mujeres había tenido el proyecto de que estudiáramos nada serio. Nuestros destinos habrían sido el secretariado y la enfermería. En cambio, todas habíamos luchado y conseguido tener estudios superiores e incluso doctorados, y trabajamos en puestos de responsabilidad con desempeños fuera de toda duda. 
vento $^{61}$, lo cuál las dejaba fuera de la sociedad y sin relación con ella. A pesar de esto los conventos se llenaban, y en el siglo XVI se estableció la clausura. Con la modernidad y la razón surgió el sujeto, el concepto de "yo" que controla el mundo. La única manera de negar a las mujeres este control era impedir que accedieran a este modo de representación: la razón. Así, los teóricos de la Ilustración y de la Revolución Francesa, Rousseau entre ellos, defendieron con todos los mecanismos de que disponían los efectos contraproducentes de la lectura y la educación de las mujeres, y la necesidad de reclusión en los estrechos espacios domésticos.

Siguiendo con la formulación de Bourdieu (1998) ${ }^{62}$ los efectos de la dominación simbólica se producen, no en la lógica pura de la conciencia, sino mediante los sistemas de percepción, emoción y acción que constituyen los hábitos -sin pasar por la conciencia ni la voluntad (también llamados memoria procedimental (Bleichmar, 199763) o conocimiento implícito (Siegel \& Hartzell, 2005 ${ }^{64}$ ). La dominación simbólica es una forma de poder que se ejerce directamente sobre los cuerpos y que se manifiesta en forma de emociones corporales -vergüenza, humillación, timidez, ansiedad, culpa- o de pasiones y sentimientos -amor, admiración, respeto. Emociones a veces muy dolorosas porque traicionan en manifestaciones visibles: el ruborizarse, la poca fluidez verbal, la torpeza, la cólera o la rabia impotentes; todas formas de someterse, a regañadientes, sin querer, al juicio dominante. También se manifiesta en acciones: anticipándose a satisfacer las necesidades del dominante ahorrándole el tener que admitir que las tiene, lo que le permite sentirse independiente y en control y parecerlo.

Termino con Bourdieu, por ahora, con otra cita literal: "Io más terrible de los efectos y las condiciones de la eficacia de la violencia simbólica es que están durablemente inscritas en lo más íntimo de los cuerpos en forma de disposiciones (hábitos), lo que hace que el poder simbólico no pueda ser ejercido sin la colaboración de los que lo sufren". Creo que sus aportaciones, aunque procedan de la sociología, son muy útiles a los/las analistas porque les permiten poder sintonizar muy finamente con las vivencias de quien se encuentra bajo la dominación.

Como veremos a continuación, de la mano de Chodorow (1994) ${ }^{65}$, Freud captó algo de lo que sucedía en la psique femenina pero no tuvo la capacidad de poner una distancia que le permitiera problematizar, cuestionar o patologizar estas posiciones subjetivas, en vez de esto, se las explicaba, las justificaba.

61. Cosa que todavía es cierta en sociedades primitivas. Hay un documental acerca del Ladakh (India) que muestra como una chica que no desea hacer el papel de esposa y madre de familia no tiene otra opción que hacerse monja budista.

62. Bourdieu, P., La dominació...

63. Bleichmar, H., Avances en psicoterapia psicoanalítica. Barcelona: Paidós, 1977.

64. Siegel, D. y Hartzell, M., Ser padres conscientes. Vitoria: La Llave, 2005.

65. Chodorow, N., Masculinities... 
Por esto Chodorow dice: "al mirar los textos psicoanalíticos sobre el género y la homosexualidad, una tiene la sensación que están minados de dominancia masculina cultural y de asunciones no cuestionadas sobre la normalidad cultural, la conformidad, la función y la causa biológica". Veamos sino lo poco riguroso de la comprensión del desarrollo, cuando presenta una visión del género normativo que no tiene en cuenta el papel del orden social, y no problematiza el deseo psicológico, la necesidad o la tendencia a ser dominante o sumisa; que da por supuesta la desigualdad inherente, la jerarquía de rol y la diferente valoración de dos tipos de personas, en relación a su constitución genital; y que trata a aquellos o aquellas que no aceptan la desigualdad y la jerarquía como neuróticas (las mujeres que no aceptan la feminidad normativa) o perversas (las homosexuales), comprometidas en una queja especial o en un rechazo a aceptar la naturaleza. Tal como afirma Chodorow, "los escritos de Freud sobre las mujeres ofrecen lo que es ser mujer en la psique de los hombres, es decir, la mujer como objeto, no como sujeto". No me consta que este libro de Chodorow haya sido traducido, por lo tanto citaré sus comentarios con cierta extensión, aunque se refieran a otros textos Freud, porque son muy ilustrativos de los efectos del ejercicio dominación simbólica por quien ostenta una autoridad científica.

Para ejemplificar, Chodorow sigue diciendo que Freud ve a los hombres como notablemente amorales en su visión del comportamiento masculino. A Freud no le Ilama en absoluto la atención el hecho de que el padre de Dora contagiara a su madre de sífilis, ni que esta enfermedad también podía haber afectado la salud de las criaturas. Tampoco condena/cuestiona el hecho de que este padre estuviera dispuesto a entregar a su hija, de 14 años, a un hombre maduro, de 40 y tantos, que estaba encantado con el regalo y que intentó forzarla.

En el caso de Paul Lorenz, el hombre de las ratas: Freud comenta, sin más, que Lorenz podía haber seducido a su hermana, y que se sentía libre de seducir y utilizar a una variedad de otras mujeres -a veces con consecuencias drásticas (parece que llevó a una al suicidio), y entonces le llama el "entrañable viejo" que tenía por costumbre hacer excursiones con las hijas jóvenes de sus amigos, y allí las masturbaba. En su análisis su única preocupación era si tenía las manos sucias y las consecuencias que esto podía tener para su salud física. Tanto el hombre del Lobo como el de las Ratas se habían iniciado a la sexualidad y al amor con mujeres sirvientes, de manera que ésta estaba infundida con imágenes de superioridad o inferioridad de clase, y de menosprecio para las mujeres, que Freud toma como característica de la resolución normal del Edipo.

En este sentido, la autora observa que hay un hilo consistente en estas historias psicológicas y culturales: la dominancia del hombre. Los hombres tienen poder familiar y social y superioridad cultural; y desde el punto de vista psicoanalítico también tienen dominancia sexual. 
En consecuencia, parte del aprendizaje de los significados de masculinidad y feminidad incluye aprender no simplemente la diferencia, sino el valor diferencial y el poder y jerarquía asimétricos. Diferencia que equivale a desigualdad y que es dolorosa para la parte inferiorizada.

En toda una serie de casos: Anna O., Elisabeth Von R., Lucy R., vemos que Freud empieza a entender la implicación del deseo sexual y del trauma sexual en la génesis de la histeria, estas mujeres tienen una subjetividad sexual con la que se debate (me refiero a su renuncia de la teoría de la seducción) y que acaba por no recoger en su teoría, en que describe a las mujeres como "casi asexuales".

Para acabar con este libro de Chodorow, dos palabras sobre el narcisismo masculino: Freud en realidad se ocupa de la distinción entre personas dotadas fálicamente y castradas (para él las mujeres son hombres castrados). En sus propias palabras, en "Fetichismo": la presencia del pene distingue al hombre, y la "Naturaleza" como precaución, ha ligado una porción de su narcisismo a este órgano particular.

A partir de la carencia de este órgano Freud describe una variedad de rasgos que, según él, caracterizan a la mujer: vergüenza de su cuerpo, celos, un menor sentido de justicia (debilidad del superyo) y narcisismo y vanidad, ya que la autoestima que un hombre centra en su pene, en una mujer se difunde defensivamente por todo su cuerpo.

Dejo apuntados los temas, que se desprenden de los textos básicos del desarrollo psicosexual femenino, que estamos rebatiendo: el sexo único masculino, la castración realizada, la sexualidad masculina de la niña, la anestesia vaginal, la sexualidad y la feminidad. Cuestiones que afectan al cuerpo de la niña y de la mujer, y que, por un lado, colocan a las mujeres en una posición subordinada, y por el otro, se siguen repitiendo acríticamente con demasiada frecuencia a pesar de haber estado rebatidas desde el mismo momento de su difusión.

En realidad ya dijo Horney $\left(1924^{66}, 1926^{67}\right)$ que cuando Freud se preguntaba ¿qué es la feminidad? se estaba preguntando como se sentiría un hombre o un chico sin pene. Dice Chodorow (1994), al volver a mirar lo que dice Freud sobre las mujeres, nos deja con una teoría normativa de la psicología femenina y la sexualidad, y con un informe rico de la masculinidad tal como se define en relación a las mujeres. Lo que falta es el relato de las mujeres.

Dio Bleichmar (1997) ${ }^{68}$ dice: ¿Se puede ser psicoanalista y no trabajar con la teoría del Edipo? Es decir, se puede trabajar con una mujer paciente y no sostener que tiene que renunciar a sus veleidades masculinoides, feministas, histéricas, arcaicas, bisexuales... todas ellas equiparadas en su inconsciente

66. Horney, K., "On the genesis..."

67. Horney, K., "The flight from womanhood", Int. J. Psychoanal., 1926, 12, pp. 360-374.

68. Dio Bleichmar, E., La sexualidad... 
con poseer un pene por medios ilícitos, con el fin de recibir un niño (mejor que una niña), que es lo que le corresponde verdaderamente, para, de esta manera atravesar el Edipo exitosamente? ¿Qué tiene que ver la maternidad ${ }^{69}$ con el placer sexual? ¿El psicoanálisis no está contribuyendo a la anestesia y a la frigidez al imponer una finalidad reproductiva a los deseos sexuales de la mujer? Por otro lado. ¿Cómo pensamos que se origina y estructura el deseo de hijo en el hombre? ¿No llama la atención que el psicoanálisis no haya estudiado este lugar en la subjetividad masculina, y que el padre sea simbólico, algo alieno y extraño? Chodorow (1994) nos muestra la incapacidad real de Freud para identificarse con las madres y su sorprendente falta de interés en las relaciones parentales.

\section{Respecto a la masculinidad}

Creo que ha quedado suficientemente claro el trabajo normativo del psicoanálisis respecto a la feminidad. En las mismas líneas se entreveía como Freud normatizava también respecto a la masculinidad. En su centenario, lo pudimos ver de forma más directa en la deconstrucción del "Análisis de la fobia de un niño de cinco años (Caso 'Juanito')" que hizo Corbett $(2009)^{70}$. El mismo título ya es elocuente: masculinidad dictada. En el artículo Corbett contempla el caso como "una ilustración ejemplar de cómo la narrativa normativa de la masculinidad ha cambiado poco durante los últimos 100 años, porque el chico que emerge de la explicación de Freud es un chico apartado de las mujeres, de sus cuerpos y de sus estados afectivos, aunque vulnerable a su belleza idealizada se enamora perdidamente- y a su generosidad. Es un chico formado a través de la competencia con los hombres y el repudio de su deseo hacia ellos. Un chico que tiene que soportar la opresión de los hombres narcisistas poderosos. Un chico que está constituido mediante el objetivo antes que el objeto", es decir, el objetivo de Freud era explicar su teoría de Edipo, que para el caso Juanito sería un cuento como este: "Mucho antes de que Juanito naciera... yo sabía que vendría un Juanito que querría tanto a su mamá que se vería empujado a temer a su papá por ello". Juanito ya era un personaje de la narrativa edípica de Freud mucho antes de que naciera. Es decir, estaba predeterminado. Tanto es así que el mismo Juanito llegó a preguntar a su padre si el Profesor hablaba con Dios, puesto que podía predecir las cosas de antemano.

Juanito fue el primer niño psicoanalítico -el sujeto fundante- a partir del que Freud (1909) ${ }^{71}$ elaboró e incorporó su teoría de la niñez (boyhood) y la

69. Tengo bastante material publicado acerca de la maternidad: Garriga, C. (2008 a,b, $2009 \mathrm{a}, \mathrm{b})$

70. Corbett, K., "Little Hans: Masculinity Foretold", The Psychoanalytic Quarterly, 2009, 68 (3), pp. 733-764.

71. Freud, S. "Análisis de la fobia de un niño de cinco años (caso Juanito)", Obras..., pp. 1365-1440. 
masculinidad. Vamos a ver un poco cuál es el contexto en el que se construye esta noción. La historia es la de una familia: padre, madre, hijo e hija. El padre de Juanito trasladaba sus observaciones a Freud, quien le asesoraba acerca de cómo tratar la fobia de su hijo a los caballos. Su padre le decía a Freud: "Teme que un caballo le morderá por la calle, y este miedo parece estar de alguna manera conectado con que a Juanito se le ha asustado con un gran pene, aunque también me pregunto si esta fobia puede expresar su ansiedad en relación con su madre". El padre de Juanito le planteaba a Freud un dilema entre apego y deseo que Freud resolvió rápidamente a favor del deseo como primario, que presiona pero que está reprimido, lo que da cuenta de la ansiedad relacionada con el deseo erótico hacia la madre, quien a su vez responde con ansiedad y amenaza a los comportamientos masturbatorios de Juanito. A pesar de que Freud había percibido su necesidad de contacto afectivo con su madre, él estaba centrado en sus ideas: la represión, y la primacía del deseo sexual hacia la madre (el Edipo).

Entonces asoció el caballo con el deseo fálico no domado, y que Juanito estaba preocupado con su pene y con su placer masturbatorio, y ansioso porque se veía inferior a aquellos que poseían un pene más grande, lo que permitió a Freud afirmar mediante su metanarrativa acerca de la "constitución sexual" como primaria, pre-discursiva y anterior a la cultura, que, los estados psíquicos llamados masculinidad se originan mediante la "función biológica" por el pene predisponente, que en este periodo está marcado no por la primacía genital sino por la primacía del falo". Además equiparaba deseo heterosexual a masculinidad. En este marco, el cuerpo del chico -su pene en particular- inicia e impulsa su experiencia subjetiva y relacional de deseo. En este marco, el pene precede al chico.

Además, Corbett, partiendo del trabajo de Lewes $(1988)^{72}$, sabe que hay doce posibles soluciones al complejo de Edipo, y conoce las consecuentes variaciones de la sexualidad y del género que pueden surgir de ellas, y que la heterosexualidad es sólo una de las doce posibilidades para el chico (y doce para la chica): sexualmente activo, con una elección de objeto de distinto sexo (anaclítica vs narcisista), escogiendo como objeto una madre castrada, y basándose en la identificación con el padre. Queda claro que resulta problemático otorgar normalidad a una única sexualidad. Tanto Lewes, como Chodorow, como Corbett, afirman que todas las sexualidades son problemáticas y que todas se tienen que explicar porque surgen del trauma y del compromiso.

Ahora sabemos, porque en el 2005 se han desclasificado de los Archivos de Freud, que la familia de Juanito estaba muy interesada en las ideas de Freud (él considera que se encuentran entre sus adherentes más íntimos), en realidad

72. Lewes, K., The Psychoanlytic theory of male homosexuality. New York: Simon \& Schuster, 1988. 
Max, el padre, hacía observaciones de la vida sexual de los niños para Freud. También sabemos que Olga, su madre, había estado en tratamiento con él, tal vez todavía la estaba tratando mientras escribía el "Caso Juanito". El matrimonio, animado por Freud, fue un fracaso. A pesar de esto, él les aconsejó que tuvieran hijos. Tuvieron a Hans y una niña 3,5 años menor, Hanna. La relación de Olga con sus hijos era mala, aunque con Hans era mejor que con Hanna, a la que literalmente, maltrataba. En cuanto fue adulta Hanna se suicidó. Por otro lado, la literatura alrededor del caso muestra una Olga muy desquilibrada con su familia y enfadada con Freud porque consideraba que Freud les había destrozado la vida.

Y lo que es llamativo del caso Juanito es la ausencia de referencias a la familia en su discusión. Freud coloca a la familia en un lugar simbólico, que no está sostenido por los datos de su vida de cada día, o, a decir verdad, los ignora deliberadamente para poder afirmar, como hace, que, la madre de Juanito es "excelente y dedicada". Pero más significativa aún es la ausencia de la madre como sujeto hablante. Por lo tanto, lo que Corbett señala es que el discurso del último siglo acerca de la masculinidad gira alrededor de estas ausencias. No obstante Corbett reconoce que en los últimos cincuenta años se ha construido una teoría angloamericana del género que, junto con la teoría psicoanalítica del desarrollo, han construido una teoría consistente que se fundamenta en la comprensión de una matriz que contempla la integración de: relación, cuerpo, mente y social.

Entonces, Corbett entiende que la experiencia de masculinidad de Juanito está construida mediante una acumulación compleja de un intercambio infinito de interacciones entre cada figura parental y el niño; entre la sociedad y el niño; entre el mundo simbólico y el niño; del niño y su cuerpo y sus genitales; de la observación de las diferencia sexuales morfológicas; y de los componentes fisiológicos. Que este proceso complejo empieza a funcionar después del nacimiento (o antes, ahora que se puede saber el sexo de la criatura desde los pocos meses de gestación), y se cruza con un desplegamiento infinito de significados conscientes e inconscientes y de mensajes enigmáticos que se traspasan de las figuras parentales a las criaturas.

Pero que lo que hizo Freud, desde su posición de autoridad, con Juanito fue darle respuestas que definían, dictaban y predeterminaban la masculinidad, una masculinidad dominante, que lleva su mancha indeleble: heterosexual, homofóbica, independiente, propulsada por el poder, que coge, que no necesita, y que no tiene lugar para el reconocimiento mutuo.

A Juanito la masculinidad le es dictada, definida, predeterminada, instalada, regulada y reforzada. A Juanito Freud le introduce mediante la interpretación lo que es y lo que no es un chico, lo que debe y lo que no debe hacer, lo que teme y lo que desea. 
Corbett ${ }^{73}$ termina su artículo dándonos su propia visión de la masculinidad en que la contempla como algo parecido a un campo de fuerzas o a un ensamblado caótico, emulando a Harris $(2005)^{74}$. Afirma que los tropos socioculturales del género se combinan con patrones sociofamiliares que a su vez son matizados por contingencias de raza, de clase y de época histórica. Esta construcción a su vez, se entreteje con el desplegamiento intrincado del cerebro, las neuronas, las hormonas y la piel. Actualmente, un siglo más tarde, en el momento que consideramos las distintas posibilidades de los chicos modernos, nos quedamos con una visión más compleja y más humilde, con un discurso con menos certidumbres, aún reconociendo el misterio de la masculinidad y los límites de nuestro alcance.

\section{Las raíces biológicas de la masculinidad}

Kernberg (1995) ${ }^{75}$ afirma que una diferencia bien establecida en el rol de género es la mayor agresividad de los chicos que Tobeña $(2008)^{76}$ relaciona inequívocamente con la testosterona. Además, los andrógenos, afirma Tobeña $(1995)^{77}$, son el ingrediente principal que influye en la intensidad del deseo sexual tanto en machos como en hembras.

A todo esto no hay que olvidar la afirmación de Chodorow (1994) ${ }^{78}$ que dice que "hay muchas evidencias de la biología moderna que muestran que la experiencia afecta a las estructuras y funciones tanto como a la inversa".

\section{Las raíces del debate psicológico respecto al aparato genital único}

Hubo un amplio debate (Dio Bleichmar, 1997) en los orígenes del psicoanálisis en que Freud y Abraham trataban de encontrar evidencias respecto al sexo único masculino, que giraba entorno a si la nena tiene una conciencia precoz de la vagina, o no, lo que daría cuenta de una sexualidad propia, femenina. Ellos sostenían que no, a pesar de que Karen Horney ${ }^{80}$ describiera la importancia de la las sensaciones vaginales precoces de la niña y de sus deseos hacia el padre, y apuntara que la envidia del pene, si existía, era secundaria al miedo por el daño que el pene del padre le podría hacer en sus

73. Di a conocer su pensamiento en Garriga, C., "Elementos para el abordaje analítico de las variaciones del género y de la sexualidad contemporáneas", www.aperturas.org, $n^{\circ} 27$, 2007.

74. Harris, A., Gender as Soft Assembly. Hillsdale: The Analytic Press, 2005.

75. Kernberg, O., Love relations. Normality and pathology. New Haven \& London: Yale University Press. 1995.

76. Tobeña, A., Cerebro y poder. Barcelona: La Esfera de los Libros, 2008.

77. Tobeña, A., El cervell...

78. Chodorow, N., Masculinites...

79. Dio Bleichmar, E., La sexualidad... pp. 187-192.

80. Horney, K., "The denial of the vagina", Int. J. Psychoanal, 1933, 14, pp. 57-70. 
genitales con sus medidas tan grandes. En este artículo también afirmaba que, tanto el clítoris como la vagina pertenecen al aparato genital femenino y que no es necesario cambiar de zona, de la sexualidad clitoridiana (masculina) a la vaginal (femenina). Acababa diciendo que las mujeres que desean "huir de la condición femenina", en realidad desean huir de la desventaja social de las mujeres en una cultura de orientación androcéntrica. Estas aportaciones no fueron incorporadas a la teoría y Freud, a pesar de su ignorancia reconocida sobre la sexualidad femenina (en la correspondencia con Abraham) siguió manteniendo la teoría del sexo único (masculino) y de la anestesia vaginal, llegando a proponer que la vagina se excitaba vía el pene interior (escíbalo) a través de las paredes de contacto.

\section{El paradigma de la intersubjetividad modifica la noción del desarrollo sano}

Jessica Benjamin (1988) ${ }^{81}$ realizó una reflexión acerca de la "madurez" psicológica y cuestionó dos conceptos hasta entonces considerados como los estadios superiores del desarrollo "sano": 1) la resolución del complejo de Edipo para alcanzar la autonomía o la independencia, tal como es en el planteamiento freudiano; 2 l) la consecución de la subfase de separación-individuación como último estadio del desarrollo propugnado por Margaret Mahler.

Si nos quedáramos con la resolución del Edipo como fase más madura del desarrollo, estaríamos aceptando como sana la noción de la autoridad paterna. Aceptar este hecho significa dar por buena la dicotomía y la "escisión psíqui$\mathbf{c a}^{\prime \prime}$ de las posiciones polarizadas, significa reconocer que la madre representa la irracionalidad y la indiferenciación (fusión oceánica), de la que nos tenemos que guardar, con la ayuda del simbolismo del padre, que representa la racionalidad y la separación. El resultado de esta "escisión", de esta estructura polarizada, es que elimina la posibilidad del reconocimiento mutuo.

El concepto de intersubjetividad de Daniel Stern (1985) ${ }^{82}$ pone en cuestión los trabajos anteriores de Mahler en el sentido que demuestra que el bebé, entre los 7 y 9 meses de vida, se da cuenta de que otra persona puede sentir lo mismo que él con gran satisfacción. Es decir, que puede establecer una conexión emocional con el otro. La criatura reconoce la existencia del otro como igual y como diferente.

Esta noción revolucionó la psicología tal como se entendía hasta entonces al introducir el aspecto realmente innovador de disfrute en la interacción, contrapuesto al de "autismo" del bebé. En la visión clásica había un sujeto que evolucionaba gracias a la acción de los objetos (la madre). Con la noción de intersubjetividad hay desde el principio dos sujetos en interacción, con la consiguiente revaloración del papel de la madre. Lo que permite el concepto

81. Benjamin, J., Los lazos...

82. Stern, D., El mundo interpersonal del infante, Barcelona: Paidós, 1991 (original 1985). 
de reconocimiento mutuo, cosa que el repudio psicoanalítico clásico de la mujer, no permitía.

Otra aportación importante de Benjamin con este ensayo es la reformulación crítica del mito de Edipo. Freud utiliza este mito para explicar nuestros deseos inconscientes y nuestro sentido de culpa inevitable, y presenta la aceptación de la autoridad paterna como sana. Al hacer eso, niega e ignora, el miedo y la sumisión que el poder paterno ha inspirado históricamente. Freud también elude el papel del padre en el mantenimiento de la fantasía de omnipotencia.

En su lectura del mito de Edipo "pasó por alto" la violencia del padre, su agresividad, su frialdad. Freud no elabora, ni analiza, el intento de Laio de asesinar a Edipo al nacer, que es el que pone en marcha el conjunto de los acontecimientos.

Si no pasamos por alto esta transgresión, como hizo Kohut $(1982)^{83}$, aparece una lectura bien diferente. Laio aparece como un padre que intenta evitar lo que es el destino de todos los padres: morir y ser sustituido por sus hijos. Es el padre edípico, el que no puede dejar la omnipotencia. La idea de su propia mortalidad, dejando su reinado a su hijo, es demasiado fuerte para él. No la puede soportar.

En la versión de Freud, Edipo aparece poseído por el deseo de matar a su padre, mientras que en la lectura que hace la autora del mito, se muestra cómo Edipo también intenta evadir la profecía. El hijo edípico es un hijo que no puede soportar su deseo de matar su padre, porque el hecho de que se cumpliera la profecía lo dejaría sin la autoridad que lo protege, sin el ideal que le da vida.

Con esta obra, ya clásica, la autora incidía en la controversia sobre Edipo y Narciso que tenía lugar en el momento de su publicación, cuyo contexto era la caída de la autoridad paterna y la búsqueda resultante de un camino diferente hacia la individuación. Hay una contradicción escondida dentro de la individualidad que los estudios sobre el narcisismo han traído a la superficie: la incapacidad de reconocer la realidad independiente del otro.

La teoría del Edipo niega la necesidad de reconocimiento mutuo entre hombre y mujer porque: a) da primacía al deseo de ser uno, b) otorga a la madre la corporalización de la fuerza regresiva, y c) habla de la necesidad de la intervención paterna para crear la parábola de que la única liberación es la dominación paterna. Yendo más allá del Edipo podemos vislumbrar una lucha directa por el reconocimiento entre hombre y mujer, sin la sombra del padre. Rechazando la falsa premisa de la autoridad paternal como la única vía hacia la libertad, nos queda afrontar la "diferencia" y hacer frente a las dificultades que surgirán, inevitablemente, de la confrontación entre iguales. Tenemos que aprender a sostener la tensión entre igualdad y diferencia entre las perso-

83. Kohut, H., "Introspection, empathy, and the semi-circle of mental health", International Journal of Psychoanalysis, 1982, 63, p. 395. Traducción en Kohut, H., Los dos análisis del Sr. Z. Barcelona: Herder, 2002. 
nas. El reconocimiento mutuo es una manera. Al incorporar al concepto de "salud" las nociones de conexión emocional y de intersubjetividad, se tiende hacia posiciones más democráticas, que incluyan a todos los seres humanos: hombres o mujeres.

El desarrollo, entonces, tendría lugar en tres etapas; 1. la preedípica prolongada, sin el repudio de la feminidad, 2. el nuevo Edipo, sin la necesidad del dominio paterno, y 3 . la postedípica, que permitiría a los hijos y a las hijas asumir la responsabilidad de los propios deseos; y al mirar atrás, y ver a sus padres, poder evaluar críticamente su herencia, sin necesidad de identificarse con su autoridad, ni tener que matarlos simbólicamente.

Lo que propone Benjamin para salir de los circuitos de la dominación es redefinir la maternidad y paternidad en dirección a la parentalidad dual, también Ilamada nuevo contrato sexual (Berbel, 2004) ${ }^{84}$ en que tanto el padre como la madre se hagan cargo de los aspectos materiales y emocionales de las criaturas. Es la solución que actualmente adoptan muchas parejas.

\section{La sexualidad femenina}

Queda claro que en el psicoanálisis clásico el concepto de desarrollo psicosexual es muy sexual y poco psicològico. Es Dio Bleichmar (1997) ${ }^{\mathbf{8 5}}$, a mi modo de ver, quien clarifica diciendo: el abordaje de la sexualidad dentro del psicoanálisis se ha vuelto naturalista. Es necesario reincorporarle la partícula psi para devolver la sexualidad a su vertiente humana. El género es el que hace este papel. El género no es un término psicoanalítico pero hay que incorporarlo.

Dio Bleichmar también reformula el psicoanálisis clásico por medio del paradigma intersubjetivo de Stern, que empieza postulando que desde el principio hay la presencia simultánea de dos sujetos vivos en interacción, la madre y la criatura. Pero le da un matiz muy particular, dice: la función del adulto de "apego" es la de proveedor de las condiciones de autoconservación de la criatura, y, simultáneamente, crea un estado que construye la mente del bebé en la medida en que hay una disimetría radical. La identificación primaria y secundaria con los padres del propio sexo constituirán un ideal de género para la criatura, que al año ya tiene establecida la diferencia de género, que no es sexual, sino excretora y social, al que el yo tiende a conformarse. Lo que a los psicoanalistas les cuesta aceptar es que la mediación por parte del adulto no lo constituye el rojo de la sexualidad sino el rosa o el azul del género.

El yo es desde su origen una representación de uno mismo genérica. Es decir, el género es uno de los atributos constitutivos del yo. Es imposible concebir

84. Berbel, S., Sin cadenas, nuevas formas de libertad en el siglo XXI. Madrid: Narcea, 2004.

85. Dio Beichmar, E., La sexualidad... 
un yo humano neutro. Para la pareja de padres el feto ya tiene sexo. Es a partir de la forma de los órganos sexuales externos del feto del bebé que se desencadena lo que John Money $(1955)^{86}$, estudioso del hermafroditismo, definió como el "dimorfismo de respuestas". La tesis de Money es que desde el origen hay un proceso de atribución de género a través de los fantasmas y expectativas de feminidad/masculinidad que hacen los padres durante el embarazo y la vida postnatal. En la estructura asimétrica de la relación adulto-criatura la pareja de padres pone continuamente en acto sus fantasmas de género; precipitados de lo histórico-vivencial de cada uno que funcionará como un troquelado -el concepto de impronta de Lorenz-y se convertirá en un esquema de género, tan inmutable como un idioma materno. En resumen, género es, según la definición de Money, un sistema de relaciones cara a cara, de los padres y familiares próximos con la cría humana durante los dos o tres primeros años de vida, a partir del cual se instituye en el psiquismo de la criatura el sentimiento íntimo de ser niño o niña. Money también postuló que los padres, a través de sus fantasmas y creencias podían generar una identidad contraria a la anatómica, pero que se revela de igual o mayor poder.

El género es una noción eminentemente psicológica que fue importada al psicoanálisis por Robert Stoller (1975) ${ }^{87}$, que habló de la identidad de género. Dio Bleichmar toma de Gayle Rubin (1975) ${ }^{88}$ el concepto de "sistema sexogénero" y deja clara la diferencia entre sexo y género: "bajo el sustantivo género se agrupan todos los aspectos psicológicos, sociales y culturales de la feminidad/masculinidad, reservando el término sexo para los componentes biológicos, anatómicos y para el intercambio sexual en sí".

Dio Bleichmar sostiene que hay una múltiple determinación del sexo biológico: cromosomas, hormonas fetales, sexo gonadal fetal, morfológico y gonadal posterior (que pueden coincidir o no -por ejemplo en las criaturas hermafroditas); y que también hay una múltiple determinación del género después del nacimiento, que, por ejemplo, para una niña comprende: las creencias de la madre sobre el destino de mujer que espera para su hija; las creencias del padre; las experiencias infantiles que dan forma a los modelos e ideales de ser mujer en el mundo; adultos que se erigen en modelos para la nena, tanto de feminidad positiva, como negativa; los modelos de feminidad vigentes en el entorno inmediato de la niña, y los que reciba por los medios. También jugaran un papel, el grado de placer y satisfacción de cada progenitor con su identidad, y el modelo de pareja que los adultos aporten a sus hijos e hijas. (Podríamos hacer un cuadro parecido para el niño).

86. Money, J., "Hermaphroditism, gender and precocity in hyperadrenocorticism: psychological findings", Bull. John Hopkins Hosp, 1955, 96.

87. Stoller, R., Sex and Gender. Nueva York: Jason Aronson, 1975.

88. Rubin, G., "The traffic in women: Notes on the 'Political Economy' of Sex". En Reiter, R. (comp.), Toward an anthopology of Women. Nueva York y Londres: Montly Review Press, 1975. 
Lo que las criaturas descubren es el conjunto del sistema sexo-género. Su metabolización constituirá la construcción individual del significado sexual que gobernará su vida psíquica determinando sus comportamientos sexuales. Por metabolización entiende la incidencia que tiene su descubrimiento para la criatura, su inscripción psíquica, o su fantasmatización, y su rechazo o aceptación.

Para explicar lo genuino de Dio Bleichmar, paso directamente al segundo tiempo de la sexualidad, al significado sexual. Dice, el niño define la feminidad como una amenaza narcisista y esto lo Ileva al repudio. La masculinidad, el género, ha hecho de la posesión y el disfrute del órgano el soporte central de la identidad masculina, lo que fundamenta que el niño normativice su masculinidad a través de la misoginia, rechace la feminidad de las niñas, se separe de la madre y repudie todo tipo de debilidad viril.

Para la niña la feminidad está situada de una forma más discontinua: teme la pérdida de amor. El ser sexuado de la nena es la gracia y la belleza en tanto que atributos del cuerpo entero.

Dio Bleichmar continua: la niña alcanza el complejo de Edipo más tarde y tiene que metabolizar la manera como la sexualidad afecta su identidad femenina, que está establecida alrededor de la maternidad. Este proceso de construcción del significado sexual es complejo, conflictivo y de difícil resolución narcisista, porque no siempre significa un "puerto seguro".

La escena originaria es la relación sexual entre los padres observada o supuesta por la criatura, que la suele interpretar como un acto de violencia por parte del padre. Tanto el niño como la niña fantasean que la madre sufre el coito. La explicación se encuentra en el momento de construcción del significado sexual donde se mezclan el esquema de género con el propio saber sobre la sexualidad. La violencia del hombre hacia la mujer no parece ser solo un fantasma ni una teoría infantil, sino una experiencia tan repetida que puede ser considerada propia de la feminidad.

La niña poco a poco va construyendo un significado del cuerpo entero como órgano sexual, y a la vez, una operatoria mental de desestimación de un significado así. Una especie de renegación y de disociación mente/cuerpo que le permite "hacerse la tonta" de la violencia a la que su cuerpo está sometido y a la que incita.

¿Qué pensamientos atribuimos a la niña cuando, situada en su papel de mujer, si quiere ser amada por el padre tiene que sufrir el coito violento? Si el formato originario pasiviza a la niña y le hace sufrir violencia tendríamos que pensar que el fantasma masoquista es la forma habitual como se sexualiza su feminidad. Para la niña la sexualidad es amenazadora, porque además de excitarla, la asusta. Habitualmente la niña, ante una escena de sexo por la tele, para dominar el miedo que le provoca recurre al romanticismo, al encubrimiento de la violencia mediante la idealización del amor. A las niñas y a las mujeres 
se las prepara para aceptar la violencia en nombre del amor. Tengamos en cuenta, además, que la mayoría de escenas sexuales en las películas, además de contener determinadas dosis de violencia, ofrecen una visión de la sexualidad femenina que no es así ni para la mayoría de las mujeres ni de las parejas: orgasmo simultáneo por penetración al medio minuto del inicio del acto.

La niña reprime fuertemente la dimensión persecutoria, de violencia y de amenaza a la integridad corporal y a la estima del yo. Y se pregunta, ¿a todas las mujeres les ocurre lo mismo, o solo a algunas? Encuentra a las mujeres divididas en dos categorías: las honradas y las ligeras, esposas y concubinas, amantes y prostitutas, "las que se dejan meter mano" y "las que no", mujeres abandonadas, violadas... Ante este panorama amenazador la niña reprime el deseo e idealiza el amor, que se convierte en garantía de su narcisismo de género y de la autoconservación de la identidad corporal.

Pero además, recurriendo a la función encubridora del mito (Robert Graves, Valabrega, Lacan) Dio Bleichmar nos hace observar como la mitología cristiana de la creación del mundo y de la persona por una figura masculina elimina el papel procreativo de la mujer, y no solo esto, sino que además descubrimos que se está realizando una inversión o un deslizamiento progresivo de la responsabilidad y la culpa de la violencia hacia la madre. Eva, o la madre fálica, son situadas en el orden simbólico: para explicar el origen de la sexualidad se propone la mujer seductora, provocadora; para dar cuenta de la tragedia mental, a la madre fálica. En la teoría del hombre sobre la mujer, del psicoanálisis sobre la niña, parece que estamos en condiciones de pensar que ha habido un apoderamiento de la narración para esconder el abuso de la violencia y contribuir a una forma de blanqueo del papel del padre que le exime de la responsabilidad que le corresponde. El cenit de este sistema de pensamiento lo encontramos en el "padre simbólico" de Lacan.

Para terminar con la tesis de Dio Bleichmar, dice "la represión sexual de la niña es de gran intensidad, llegando incluso a la inhibición". Una de sus manifestaciones es la ausencia de masturbación. Dio Bleichmar se pregunta: Las niñas que se apartan de cualquier interés sexual ¿son menos femeninas que las que se masturban? Las mujeres que Ilegan a la vida adulta sin haberse masturbado ¿son mujeres con trastornos de su identidad femenina? Son legiones las mujeres que acuden a las consulta en busca de ayuda por serios conflictos en torno a la feminidad y masculinidad de sus aspiraciones, expectativas, actividades: por problemáticas en torno al género. Lo que prevalece es el rechazo mayúsculo o simplemente el abandono de los modelos de feminidad que la preexisten. Yo añado: y toda esta conflictiva comporta sufrimiento, por presiones externas a conformarse al estereotipo o por exigencias internas debidas al género internalizado. Además las mujeres presentan otra problemática alrededor de la sexualidad, con cientos de mujeres con conflictos en torno al deseo sexual y al orgasmo, así como una enorme incidencia de abusos sexuales infantiles con sus consiguientes implicaciones para la vida psíquica y sexual 
adulta, que hace que apenas haya mujeres que atiendo que no hayan sufrido algún tipo de abuso infantil por parte de adultos próximos.

En realidad la autora, ya en $1984^{89}$, describía toda esta complejidad, y mostraba el tormento que la sexualidad ocasionaba a las mujeres que deseaban tener experiencias y relaciones, satisfacer el deseo con la misma facilidad y falta de sanciones morales y personales que caracteriza la práctica sexual de los hombres. La histeria, la represión psicológica, correlato psíquico de la represión social de la sexualidad femenina imperante a principios del siglo XX, era expresión patológica del conflicto que vivía entre, por un lado, estar socializadas para ser objeto de deseo, símbolo sexual, pero por otro, tener que ser las encargadas del control del deseo sexual, es decir, de seducir a los hombres pero sin respuesta emocional por parte de ellas. A principios del XXI las mujeres ya no sufren porque han tenido relaciones sexuales ilícitas o múltiples, sino porque no las tienen. El conflicto actual se configura entre tres variables: la hipervaloración del atractivo sexual; la negación de los riesgos de la integridad corporal y la ilusión de control (Dio Bleichmar, 2000) ${ }^{90}$.

Sigue Dio Bleichmar, las niñas adquieren durante la latencia un saber: la sexualidad marca a las mujeres y no a los hombres (un ejemplo lo tenemos en "puta" e "hijo de puta"), es decir, que hay una diferencia radical en la legitimación de los comportamientos sexuales de los hombres y de las mujeres, al punto que "la legitimidad que tiene el adulto para la caricia sexual de la niña es extensiva a su práctica sexual de toda clase, de manera que el delito sexual no le genera ni vergüenza ni culpa. Por lo tanto, la mayor dureza de la represión de la sexualidad por parte de la niña se vincula a este saber sobre la sexualidad adulta que sitúa a cualquier niña ante la necesidad de confrontar y negociar un significado sexual que incluye: una valoración negativa de la identidad femenina de la niña sexual; un riesgo de violencia sexual ${ }^{91}$; y la constatación de la ausencia de juicio condenatorio en el comportamiento sexual masculino, por el otro.

Ya en la pubertad, la época del desarrollo más crítica para la niña, se le generan una serie de ansiedades sobre la integridad de su cuerpo y sobre las consecuencias indeseables que la satisfacción del deseo sexual puede conllevar que no tiene su contraparte en los temores de castración del niño. Para la niña, si estos temores se articulan con el fantasma de la escena primaria sádica, la sexualidad femenina adulta pasa a ser una amenaza real, y por lo tanto, un factor traumático.

89. Dio Bleichmar, E., El feminismo espontáneo de la histeria. Madrid: Adotraf, 1985.

90. Dio Bleichmar, E., "Incidencia de la violencia sexual sobre la construcción de la subjetivad femenina", en Hernando, A. (ed.), La construcción de la subjetividad femenina. Madrid: Instituto de Investigaciones Feministas de la Universidad Complutense, 2000.

91. En los Sanfermines 2008 una estudiante de enfermería (Nagore) fue asesinada por el psiquiatra José Diego (autor confeso) por haber tenido la osadía de seducirle y no querer mantener relaciones sexuales completas. 
En resumen la tesis de Dio Bleichmar es que la sexualidad femenina es muy compleja por toda esta serie de razones: en primer lugar porque es la totalidad de su cuerpo el sexualizado, sin un reconocimiento de sus órganos -se excita pero no se entera, por un mecanismo de escisión que le permite que la conciencia no se entere pero que se articule un movimiento de seducción, que, si es reconocido por la mirada del hombre, le devuelve una implantación exógena del deseo, junto con una acusación de provocadora y seductora. Y con una prohibición muy explícita de tocarse los genitales. Y teniendo que hacer, además, otra escisión en torno a la violencia, que idealiza en nombre del amor.

En sus palabras: "lo que constituye la "mascarada" de la feminidad es, en realidad, su sexualización, la forma de sexualización de su imagen que le viene impuesta por mandato de género y que contribuye a la escisión, clivaje, disociación en el inconsciente de una tenaz resistencia a aceptar tal identidad. Tanto si es aceptada o rechazada será a costa de sufrimiento". En otras palabras: "nos encontramos que aquello que perturba a la feminidad es la feminidad misma tal cual está establecida, la sexualidad femenina con sus riesgos reales, la identidad femenina misma con sus desventajas en una cultura que mitifica y devalúa la feminidad".

En otro artículo Dio Bleichmar (2000) $)^{92}$ completaba diciendo que hay una realidad de desigualdad entre los géneros que instituye a la feminidad y a la condición maternal como un objeto de deseo que encubre una profunda y milenaria discriminación.

Además, la vivencia que se inicia en la infancia de ansiedad, culpa, sexualización exógena, falta de control emocional y falsificación de su propia vivencia, ante la experiencia sexual de las mujeres, puede prolongarse a lo largo de la vida si no se interpone un trabajo psíquico de reconocimiento del atrapamiento intersubjetivo en el que se halla.

Su propuesta $(1997)^{93}$ : 1. "Si la niña está deificada en una imagen corporal que se constituye en un todo, será necesario desexualizar sus representaciones".

2. "Si la niña está sumida en el desconocimiento de sus órganos y de sus placeres, será necesario darlos a conocer y legitimarlos para que la zona erógena sea investida sin que angustias persecutorias o de culpabilidad se lo impidan".

Ethel Person (1999) ${ }^{94}$ abunda en la visión que el sistema dimórfico normativo genera dos organizaciones de la sexualidad que en los extremos puede resultar problemáticas, que denomina hiposexualidad, o inhibición de la sexualidad en las mujeres, e hipersexualidad masculina.

92. Dio Bleichmar, E., "Incidencia de la...".

93. Dio Bleichmar, E., "La sexualidad...".

94. Person, E. S., "Sexuality as the Mainstay of Identity", 1980, en The Sexual Century. New Haven and London: Yale University Press, 1999. 
Respecto a la inhibición Person se refiere a dos tipos de fenómenos: 1) las inhibiciones de la asertividad (capacidad de una persona de saber lo que quiere y de hacer lo posible para conseguirlo) en un contexto interpersonal, y 2) las inhibiciones del sexo en sí (del deseo, de la excitación o del orgasmo) también denominado bajo impulso sexual.

1. Las inhibiciones de la asertividad tienen que ver con el comportamiento de deferencia o el miedo al hombre. Incluyen: falsear el orgasmo, no insistir en la estimulación adecuada, asumir que el orgasmo del hombre acaba la relación y poner más atención en complacer que en ser complacida.

2. Respecto al bajo deseo sexual, se refiere a los bajos índices de masturbación en las chicas y las mujeres, y en la capacidad para tolerar la anorgasmia, que a su vez están relacionados con la asertividad y con el hecho que muchas mujeres sean más reactivas que autónomas al respecto.

Sigue Person, los cambios en la manera de vivir la sexualidad las mujeres, orientados a la obtención de placer y a la autoexpresión, vendrán de alcanzar las condiciones necesarias para su desarrollo como sujetos, es decir, la liberación sexual viene de la liberación personal, y no al revés. Sara Berbel $(2004)^{95}$ lo plantea en estos otros términos: difícilmente se puede vivir una relación sexual en libertad, simetría y reciprocidad si los dos miembros de la pareja no gozan de independencia al mismo nivel, psicológica, económica y social; circunstancia cada vez más frecuente aunque no mayoritaria en nuestra cultura.

\section{El caso John/Joan o Brenda/David ${ }^{96}$}

La historia del género en el psicoanálisis se suele remontar a este caso. Corría el año 1955 y el endocrinólogo John Money, que trabajaba con hermafroditas, tuvo la oportunidad de "verificar" una hipótesis con la que venía pensando, puesto que le llamaron unos padres de un niño de un año y ocho meses, muy preocupados porque en una intervención de fimosis se le había cauterizando el pene.

Estos padres vieron a Money por la televisión hablando de cirugía transexual, donde presentaba el punto de vista de que si a una criatura se la somete a cirugía y se la socializa en un género diferente del que le fue originalmente asignado al nacer, podría desarrollarse normalmente, adaptarse perfectamente bien al nuevo género y vivir una vida feliz.

95. Berbel, S. Sin cadenas...

96. Sacado de Butler, J., "Hacerle justicia a alguien: La reasignación de sexo y las alegorías de la transexualidad", en Deshacer el Género, Barcelona: Paidós. 2004, pp. 89-112 y de FaustoSterling, A., "The five sexes, revisited", en The Sciences, 2000, pp. 19-23. 
Los padres de David se pusieron en contacto con este doctor, quien les invitó a visitarle a Baltimore, a la John Hopkins University, donde David fue reconocido por el equipo médico y el Dr. Money recomendó enérgicamente criar a David como chica. Los padres estuvieron de acuerdo; a David le extirparon los testículos y le hicieron una preparación preliminar para el implante de una vagina, pero decidieron esperar a completar la operación hasta que Brenda -este era el nuevo nombre del niño- fuera más mayor.

Así pues Brenda creció como una chica; se la controlaba a menudo y se la trasladaba periódicamente al Gender Identity Institute de John Money para vigilar su adaptación como chica. Más tarde, cuando contaba ocho o nueve años, Brenda manifestó su deseo de comprar una pistola de juguete. Aunque no tenía pene, a Brenda le gustaba orinar de pie. Se la sorprendió una vez en el colegio y las chicas amenazaron con "matarla" si continuaba.

Los equipos psiquiátricos le ofrecieron estrógeno pero ella rehusó tomarlo. Money intentó hablar con ella acerca de la obtención de una vagina pero Brenda se negó. También le enseñaron fotografías de órganos sexuales para que conociera y deseara la así llamada normalidad de los genitales no ambiguos. De hecho salió gritando de la consulta. En otra ocasión le enseñaron fotografías sexualmente explícitas, y se les llegó a pedir, a ella y a su hermano, que representaran falsos ejercicios cóitales entre ellos según las órdenes que iban recibiendo. Más tarde explicaron que se sintieron muy asustados y desorientados por esa orden y que en aquel momento no se lo dijeron a sus padres. Brenda prefería las actividades masculinas y no le gustó que se le desarrollaran los pechos.

Los psiquiatras locales de Brenda creyeron que se había cometido un error en la reasignación de sexo. Entonces fue examinada por Milton Diamond, un investigador de la sexualidad que cree en la base hormonal de la identidad y que ha estado luchando contra John Money durante varias décadas. Este nuevo grupo médico ofrecieron a Brenda la posibilidad de cambiar de ruta y ella aceptó. Empezó a vivir como un chico llamado David, a la edad de catorce años. Entonces David empezó a solicitar y a recibir inyecciones de hormonas masculinas y se le extirparon los pechos. Entre los 15 y los 16 se le implantó un falo, con el que no eyaculaba aunque sentía cierto placer sexual, y orinaba por su base.

Durante el tiempo que David fue Brenda, Money continuó publicando artículos en los que se ensalzaba el éxito de este caso de reasignación de sexo, y que Brenda era feliz, aunque rehusaba adaptarse a muchos "comportamientos de chica" y la asustaban e irritaban los constantes e intrusivos interrogatorios de Money. Sin embargo Money afirmaba "que la puerta de la identidad de género está abierta en el nacimiento y permanece abierta durante al menos más de un año después de nacer".

El caso fue utilizado por los medios de comunicación para demostrar que lo que es femenino y lo que es masculino puede ser alterado y que estos términos 
culturales no tienen un significado fijo o un destino intrínseco, y que son más maleables de lo que previamente se pensaba.

Brenda fue sometida por Money y por su equipo a multitud de entrevistas, también la llevaban a charlas con transexuales de hombre a mujer: se le preguntaba una y otra vez si se sentía como una chica, cuáles eran sus deseos, cuál era su imagen del futuro, si incluía el matrimonio con un hombre. A Brenda también se le pedía que se quitara la ropa y que mostrara sus genitales a médicos en prácticas y a los que controlaban el caso.

Se ha criticado a Money por lo rápidamente que trató de utilizar a Brenda como ejemplo de las propias creencias teóricas acerca de la neutralidad del género o sobre el papel primario de la socialización en la producción de la identidad de género.

Por otro lado, Milton Diamond sostiene que a David le parecía insoportable vivir como una chica, y que esto da cuenta de un sentido del género ligado a los genitales iniciales y que parece una verdad interna, una necesidad, que no puede ser invertido, no importa qué cantidad de socialización se emplee, es decir, que hay un núcleo esencial del género (gender core) que está ligado a la biología. Diamond afirmó en una entrevista que los ensayos de Money "ya han sido utilizados como uno de los principales fundamentos del feminismo moderno". Aunque David dice sobre si mismo:

“Desde muy pronto noté pequeñas cosas. Empecé a ver cuán diferente me sentía y era de lo que se suponía debía ser. Pero no sabía qué significaba. Pensé que era una persona anormal o algo así. Me miraba a mi mismo y me decía que no me gustaba este tipo de ropa, no me gustaban los tipos de juguetes que siempre me daban. Me gustaba estar con los chicos y subirme a los árboles y cosas como ésas, pero a las chicas no les gustaba hacer este tipo de cosas. Me miraba al espejo y [veía] que mis hombros [eran] muy anchos, quiero decir, no [había] nada femenino en mi. [Era] delgado, pero a parte de eso, nada. Pero así [fue] como me di cuenta [de que era un chico] pero no quería admitirlo. Me di cuenta de que no quería abrir la caja de los truenos" (Diamond y Sigmundsen).

A pesar de esto, lo que defiende la Sociedad Intersexual de Norteamérica es que ni la presencia del cromosoma $Y$ es óbice para que se les someta a cirugía, y menos que se les asigne el sexo femenino simplemente porque es más fácil producir un conducto vaginal que construir un falo, ya que, aunque es cierto, como defiende Fausto-Sterling que debe asignarse un sexo a las criaturas con el fin de establecer una identidad social estable, no se puede concluir por ello que la sociedad deba dedicarse a realizar cirugía coercitiva para rehacer un cuerpo según la imagen social del género escogido. El género es un tipo de 
identidad y su relación con la anatomía es compleja ${ }^{97}$. De acuerdo con Cha$\mathrm{se}^{98}$ (Presidenta de Intersex), la criatura al madurar puede escoger cambiar de género o, incluso, elegir la intervención hormonal o quirúrgica, pero dichas decisiones están justificadas porque están basadas en una elección informada. Sin embargo, la investigación ha mostrado que a menudo estas operaciones quirúrgicas han sido realizadas sin el conocimiento de los padres, sin que se les haya verdaderamente comunicado a las propias criaturas y sin esperar a que fueran suficientemente mayores como para dar su consentimiento. En cierta manera, todavía es más sorprendente el estado de mutilación en el que se deja a estos cuerpos, las mutilaciones que se realizan y que luego paradójicamente se justifican en nombre de una "apariencia normal". El caso Brenda/David ha mostrado la brutalidad, la coerción y el daño pertinaz causado por las cirugías no deseadas que se realizan sobre las criaturas intersexuadas.

Fausto-Sterling se pregunta: ¿Quién es intersexual y cuantos hay? El hombre y la mujer, ideales platónicos, apenas existen. Muchas mujeres tienen pelos en la cara, algunos hombres no tienen; algunas mujeres hablan con voz muy grave, mientras que algunos hombres la tienen muy aguda; los cromosomas, las hormonas, las estructuras sexuales internas, las gónadas y los genitales varían mucho más de lo que creemos. Actualmente se considera que nace en una condición intersexual el $1,7 \%$ de todas las criaturas vivas. Esta cifra no es uniforme en todo el mundo. Por ejemplo el gen de la hiperplasia adrenal congénita varía mucho. Mientras que en Nueva Zelanda hay 43 criaturas por millón, entre los esquimales su frecuencia es de 3500 por millón.

El movimiento intersex propone, en cambio, imaginar un mundo en el cual los individuos con atributos sexuales mixtos puedan ser aceptados y amados sin tener que transformarlos en una versión socialmente más coherente o más normativa del género. Cuestionan el ideal del dimorfismo de género a la luz de la variabilidad de posiciones posible dentro del continuo entre varón y hembra y por tanto denuncian la falsedad de dicho dimorfismo como prerrequisito hu-

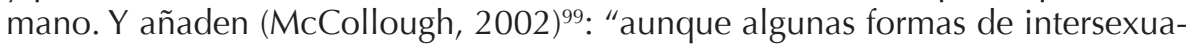
lidad pueden estar acompañadas de ciertos estados de enfermedad, y requerir

97. Mientras estoy trabajando en este artículo, escucho por la radio la noticia de que una chica de 16 años acaba de pedir autorización al juez, porque la ley permite esta intervención a menores de edad si tienen autorización judicial, para poderse hacer un cambio de sexo, a chico, con el que todo el mundo está de acuerdo. Ella misma, por supuesto, sus padres y los médicos de la unidad de trastornos de género del Hospital Clínico de Barcelona. La conveniencia de realizar esta intervención cuanto antes estriba en los riesgos mucho mayores de una amputación cuando los pechos están bien desarrollados. La chica está bien informada y hace casi dos años que está en tratamiento hormonal y psiquiátrico, por lo que es un caso claro que no presenta dudas a nivel médico y sobre el que hay un dictamen favorable de los forenses.

98. Chase, Ch., "Hermaphrodites...".

99. McCullough, L. B., "A framework for the ethically justified clinical management of intersex conditions", 2000, en Zderic et al. (eds.), Paediatric Gender Assignment: A Critical Reappraisal. Academia/Plenum Publishers, 2002. 
intervenciones -como la hiperplasia adrenal congénita antes mencionada-, las condiciones intersexuales no son enfermedades en sí, por lo tanto los médicos tendrían que abandonar su práctica de tratar el nacimiento de una criatura con ambigüedad genital como si fuera una urgencia médica o social, en lugar de eso, deberían tomarse tiempo para elaborar un protocolo médico minucioso que los ayudara a exponer toda esta complejidad a los padres, con las incertidumbres sobre el resultado final incluidas, y por lo tanto el tratamiento de elección tendría que ser la psicoterapia no la cirugía".

Mientras que Money consigue que aleccionen a Brenda en nombre de la normalización, Diamond prescribe a David el protocolo de cambio de sexo de la transexualidad con el fin de que reafirme su destino genético en nombre de la naturaleza. De hecho, podemos decir que juntos Brenda/David soportaron dos cirugías transexuales: la primera basada en un argumento hipotético sobre lo que debería ser el género dada la naturaleza amputada del pene; la segunda basada en lo que debería ser el género a tenor de las indicaciones verbales y de la conducta de la persona en cuestión. En ambos casos, se hacen ciertas inferencias que sugieren que un cuerpo debe ser de cierta manera para que el género funcione.

David lo sabía, hasta cierto punto, porque dice:

"El doctor me dijo: 'será duro, te van a molestar, estarás muy solo, no encontrarás pareja, (a menos que te hagas la cirugía vaginal y que vivas como una mujer'). Yo no era muy mayor en aquel momento, pero me di cuenta de que estas personas debían de ser bastante superficiales si eso es lo único que piensan que tengo; si creen que la única razón por la que la gente se casa y tiene niños y una vida productiva es a causa de lo que tienen entre las piernas... si eso es lo que piensan de mí, si se me valora por lo que tengo entre mis piernas, entonces debo de ser un absoluto perdedor."

Aquí David se niega a ser reducido a una parte del cuerpo. Se tiene en más estima que los doctores. Y nos está diciendo que hay una inconmensurabilidad entre quien es y lo que tiene; que para amar y ser amado se precisa algo más. Fausto-Sterling nos informa que David se casó con una mujer con hijos, a los que adoptó.

El 5 de Diciembre de 2004 David se suicidó, a la edad de 38 años. Su hermano había muerto hacía dos años y él estaba separado de su mujer. Es difícil saber qué fue lo que, al final convirtió su vida en inhabitable o por qué sintió que era el momento de finalizarla. Pero lo que parece claro es que los conflictos y dificultades alrededor del género y su "tratamiento" contribuyeron decisivamente a un sufrimiento pertinaz.

Traigo este caso y sus vicisitudes para que sigamos pensando en la complejidad y en la iatrogenia. Hablar de sistema sexo-género es tener en cuenta 
la multifactorialidad de las variable intervinientes en la configuración del self de cada sujeto dado.

\section{El siglo XXI}

Esta primera parte la abordaré de la mano de Virginia Goldner (2003) ${ }^{100}$. Las lecturas que he citado hasta el momento (Chodorow, Dio Bleichmar y Benjamin) estaban todavía muy sujetas a la obra de Freud, pero la lectura deconstructiva de de Lauretis (1990) ${ }^{101}$, permitió comprender la fuerza reguladora de la cultura que insiste en la idea de dos sexos "opuestos" y mutuamente excluyentes que se mantiene en pie por la acción patógena de la escisión psíquica. Butler (1990) ${ }^{102}$ demostró que el género en realidad crea la misma subjetividad puesto que "las personas solo devienen inteligibles cuando se convierten en 'generadas'.

De tal manera que quedó claro (Goldner, 1991 ${ }^{103}$, 2003 ${ }^{104}$ ) que la construcción psíquica del género requería la alienación de la subjetividad; que cualquier pensamiento, acto, objetivo, u objeto erótico que fuera culturalmente incongruente con la feminidad o la masculinidad normativas tendrían que ser rechazados, extinguidos o disfrazados.

En definitiva, la estructura y/o paradigma de género constituye una "situación patógena universal" que induce a un sistema de falso self traumáticamente sumiso que, en si mismo, produce una multitud de síntomas e innumerables formas de sufrimiento no reconocidos como tales: la melancolía y la homofobia; el trauma narcisista que constituye la feminidad como un sexo de segunda categoría, la agresividad defensiva y la hipersexualización de la masculinidad normativa (Person, 1980) ${ }^{105}$, la relacionalidad depresiva y la inhibición de la capacidad de actuar ("agency") y del deseo que constituye la feminidad normativa (Butler, 1993 ${ }^{106}$, Dio Bleichmar, 1991 ${ }^{107}$; Chodorow, $1999^{108}$, Layton, $\left.1998^{109}\right)$.

100. Goldner, V., "Ironic Gender/Authentic Sex", Studies in Gender and Sexuality, 2003, 4 (2), pp. 113-139.

101. De Lauretis, T., "Eccentric subjects: feminist theory and historical consiousness", Feminist Studies, 1990, 16, pp. 115-150.

102. Butler, J., Gender Trouble. New York: Routledge, 1990.

103. Goldner, V., "Relational psychoanalysis and the postmodern turn", en Fairfield, S., Layton, L. y Stack, C. (eds.), Bringing the plague: Toward A Postmodern Psychoanalysis. New York: Other Press, 1991.

104. Goldner, V., "Ironic Gender...".

105. Person, E. S., "Sexuality as...".

106. Butler, J., Bodies that Matter. New York: Routledge, 1993.

107. Dio Bleichmar, E., La depresión en la mujer. Madrid: Temas de Hoy, 1991.

108. Chodorow, N., The Power of Feelings. New Haven \& London: Yale University Press, 1999.

109. Layton, L., Who's that girl? Who's that boy? Hillsdale: The Analytic Press, 1998 (Reedición: 2004). 
La teoría del género postmoderna

El giro postmoderno atacó la propia categoría de género, monolítica y transhistórica porque demostró que el género está en si mismo constituido y estabilizado por una red de oposiciones culturales e interimplicadas; opuestos que se refuerzan mutuamente.

A medida que el género empezó a desintegrarse, gracias a la teoría postmoderna, cambió su centro de interés y pasó a teorizar la "diferencia". La acción psíquica del género fue concebida como análoga a la acción de otros binomios culturales: la raza, el sexo, la clase social. Cada una de estas (falsas) oposiciones fue considerada como una ejemplificación del proceso patógeno a través del cuál, variaciones inapreciables (en el tono de la piel, en la morfología corporal, en la preferencia sexual, en el nivel de ingresos) podían transformarse en polaridades simplistas (blanco-negro, hombre-mujer, gay-hetero, rico-pobre) elevando a normativo el "nosotros" (hombres, blancos, heterosexuales, ricos) por encima de un estigmatizado "ellas/os" (mujeres, negros, homosexuales, pobres).

Por otro lado, el género no sólo actúa sobre nosotros, también es un tropo cultural disponible para nosotros, un tropo que en realidad puede ser desplegado por el sujeto al servicio de sus propios objetivos, incluida la subversión de los mismos imperativos de género.

Conceptualizar el género en tanto que "recurso simbólico" es un giro postmoderno que nos Ileva más allá de la perspectiva del género como un proceso lineal "de fuera a dentro". Sobretodo Butler (1993) ${ }^{110}$ y Harris (2005) ${ }^{111}$ han aportado argumentos que muestran como el sujeto metaboliza y reelabora el "afuera" en un acto de resignificación creativa, cosa que ha permitido construir puentes entre feminismo y psicoanálisis, históricamente escindidos a cada lado del binomio "dentro-fuera" con las feministas estudiando las maneras en que las fuerzas sociales y culturales construyen a los sujetos y las psicoanalistas centradas en la miríada de procesos mediante los cuales los sujetos se inventan a si mismos a pesar de todo.

El género entonces estaría construido como una identidad social fija $y$ un estado psíquico fluido, constituido en la tensión entre la "objetificación" (sea como sea definida en un contexto cultural y familiar particular) y la capacidad de actuación (el proyecto continuo de autocreación individual de un sujeto) (Goldner, 2003) ${ }^{112}$.

110. Butler, J., Bodies...

111. Harris, A., Gender...

112. Goldner, V., Ironic... 


\section{El género personal}

Como todas las explicaciones esquemáticas, la teoría psicoanalítica del género no puede presuponer como están entretejidos el deseo y la identificación en la creación personal del género en la vida de cualquier individuo, porque el género es personal (Chodorow, 1999113, Layton, $1998^{114}$, Harris, 2000 ${ }^{115}$ ); cada uno/a crea una versión del género únicamente personal, modulado dinámicamente, relacionalmente inteligente y ensamblado a partir de los tropos de género que cada cultura y periodo histórico dejan disponibles.

El tema, por tanto, no es el género per se, sino cuán rígida y concretamente se utiliza en una mente individual o en un contexto familiar y qué trabajo psíquico e intersubjetivo despliega; la cuestión es la medida en que el sujeto se experimenta a sí mismo como confiriendo significado al género, o si el género es un "significado que tiene lugar en él/ella" (Goldner, 2003)"

Hablando del giro postmoderno es imprescindible un paseo por los conceptos de Judith Butler. Para ello me basaré en una reseña mía (Garriga, 2008a) ${ }^{117}$. Butler afirma que "ser mujer no constituye un hecho natural sino una realidad cultural constituida gracias a actos realizativos o performativos. La performatividad es aquello que impulsa y sostiene la acción gracias a un proceso de repetición que va creando realidad por reiteración, persistencia y estabilidad. Pero la performatividad también tiene capacidad de ruptura con contextos anteriores y de asumir ilimitadamente otros. La fuerza de los preformativos reside en que no es separable del cuerpo como acto corporal, incluido el habla, el lugar de la historia incorporada.

Butler considera insuficiente que se entienda el género como la variable cultural de la construcción del sexo. En cambio postula que el género y el deseo sexual son flexibles, que flotan libremente y que no están causados por otros factores estables. En concreto, Butler, tiene una concepción de la libre elección de la identidad sexo-género que rompe con posiciones esencialistas: cualquier persona puede tener cualquier grado de feminidad y de masculinidad; despatologiza las opciones sexuales alternativas (denuncia la heterosexualidad compulsiva y reconoce cualquier posibilidad del deseo: homosexual, bisexual, transexual); y desvincula la idea de que la identidad primaria se afinca en un sexo biológicamente dado, constante, inalterable e inevitable. Según la teoría de los actos preformativos de Butler, el sexo-género, es una actuación

113. Chodorow, N., The power...

114. Layton, L., Who's...

115. Harris, A., "Gender as soft assembly: Tomboys' Stories", Studies in Gender and Sexuality, 2000, 1(3), 223-251.

116. Goldner, V., Ironic...

117. Garriga, C., "Elementos para el abordaje analítico de las variaciones del género y la sexualidad contemporáneas: Judith Butler (Cleverland, Ohio, 1956)" www.aperturas.org, n 28, 2008a. 
repetida, ritualizada y legitimada, que hace explícitas las leyes sociales o las altera (Femenías, 2003) ${ }^{118}$.

El concepto de agencia (capacidad de acción) es central en la obra de Butler y lo entiende como el carácter preformativo del significante político. Esto significa que "estoy constituida por un mundo social que no he escogido". Como resultado, el "yo" que soy está constituido por normas y depende de ellas, pero también aspira a vivir de maneras que mantengan una relación crítica y transformadora de las normas, entendiendo la crítica como un cuestionamiento de los términos que restringen la vida con el fin de abrir modos diferentes de vida, no tanto para celebrar la diferencia en sí misma, sino para establecer condiciones más incluyentes que acojan la vida que se resiste a los modelos de asimilación.

La teoría de los actos preformativos permite a Butler salir del orden binario de los sexos-géneros regulados por la matriz de la heterosexualidad compulsiva y le permite teorizar la proliferación de géneros paródicos. El sexo-género es una actuación repetida, ritualizada y legitimada que hace explícitas las leyes sociales. El determinismo lo constituye la repetición estilizada de actos desplegada en el tiempo, no se trata de una elección radical, de voluntarismo, ni de una imposición ciega. Todos llevamos una representación de género, sea tradicional o no. Por lo tanto no se trata de si hacer una actuación de género, sino de qué forma toma esta actuación. Al escoger la propia puede ser que trabajemos para cambiar las normas del género y la comprensión binaria de entender la masculinidad y la feminidad.

\section{Conclusiones}

Como psicoanalistas trabajamos desde el caso por caso, que cada persona es única y es resultado de cómo se ha configurado su identidad a partir de la matriz relacional, emocional, cultural y social en la que ha crecido; su identidad de género se ha forjado en un diálogo performativo con la cultura respecto a los significados de la masculinidad y la feminidad (D'Ercole \& Drescher, 2004) $)^{119}$. El género, entonces, está determinado culturalmente, pero sin embargo se crea individualmente, es permeable y a la vez corporizado, simultáneamente inventivo y defensivo, y tiene una estructura esencialmente relacional. Esta definición es la materialización de la teoría psicoanalítica del género, con raíces clínicas, que ha pasado por la teoría queer y la deconstrucción, y que ahora consiste en reensamblar el género de modo que no se re-esencialice (Harris, 2005) ${ }^{120}$.

Las creencias sobre el género -lo que creemos acerca de nuestro género y lo que creemos acerca de los otros- están en el aire que respiramos y son

118. Femenías, Ma L., Judith Butler (1956). Madrid: Ediciones del Orto, 2003.

119. D'Ercole, A. y Drescher, J., Uncoupling Convention: Psychoanalytic Approaches to Same-sex Couples and Families. Hillsdale: The Analytic Press, 2004.

120. Harris, A., Gender... 
tan invisibles como el aire. Además a menudo se dan por supuestas y están incrustadas en el hacer, lo que las hace difíciles de analizar. Estas creencias se transmiten de fuera a dentro del self, y, puesto que las culturas cambian con el tiempo, las creencias acerca del género también lo hacen.

El género personal y las vivencias a su alrededor son un tema clínico importante, independientemente de la razón por la que un/una paciente inicie un tratamiento. También es importante que, como terapeutas, reflexionemos sobre nuestras creencias acerca del género, y sobre nuestra posición de género personal. Mi propuesta (Garriga, 2006 ${ }^{121}, 2009^{122}$ ), hoy, es que el género debe ser un ingrediente constitutivo de la psicoterapia, que en algunos momentos será explícito, como parte del diálogo terapéutico, pero que en todo momento estará implícito, tanto en el hacer del/la paciente, como en el del/ la terapeuta. Que, por tanto, tiene que estar en la mente del/la terapeuta en tanto que reflexión permanente sobre la propia posición y como aspecto a monitorizar de la posición de nuestros y de nuestras pacientes.

Además, Bourdieu (1998) ${ }^{123}$ sostiene que una simple conversión de la conciencia y de la voluntad no son suficientes para erradicar la violencia simbólica, sino que es necesaria una transformación de las estructuras que crean las disposiciones para su ejercicio.

Hernando (2003) $)^{124}$ por su parte, sigue explicando que cuando, por fin, las mujeres accedieron a la escolarización tuvieron que enfrentar distintos conflictos. Uno: que la mitad masculina (e inmadura, y enferma) de la población no podía ni quería renunciar al cuidado y a las atenciones que hasta entonces tenía garantizadas (y sin las cuáles resulta mucho más difícil mantener el equilibrio de poder). Dos, interno: el modelo de identidad de género que las mujeres siguen recibiendo continúa dando prioridad a los afectos. Por lo tanto, escoger la individuación que les permita acceder a la posición de sujetos sociales, de equidad y de justicia social, no es fácil, sino al contrario, las mujeres que escogen ser sujetos saben que están escogiendo una opción difícil, de soledad y de esfuerzo constante; y que tienen que tener ganas porque tienen que renunciar a una percepción impotente y mítica de la realidad a fin de asumir la parte de soledad, responsabilidad e incertidumbre que comporta.

Escoger la individuación supone modificar las disposiciones que generan dominación y subordinación. Las mujeres que quieran hacerlo saben que tie-

121. Garriga, C., "Les dones del segle XXI ens volem Iliures per ser i fer", Full Informatiu del COPC, 2006, 119.

122. Garriga, C., "Aplicaciones del modelo relacional a las subjetividades femeninas contemporáneas, en concreto a la maternidad, más allá del destino biológico y psicológico", CelR on-line, 2009, 3 (1), pp. 150-164. [Disponible en: http://www.psicoterapiarelacional.es/ LinkClick.aspx?fileticket=f4sAP98ZTkI\%3d\&tabid=442].

123. Bourdieu, P., La dominació...

124. Hernando, A., "Poder, individualidad e identidad de género femenina" en Hernando, A., (coord.), ¿Desean las mujeres el poder? Madrid: Minerva Ediciones, 2003. 
nen que salir de la indefensión en la que las dejan los criterios que las definen al servicio de la dominación. Tendrán que hacer esfuerzos para empoderarse, para pasar de la posición de objetos a la de sujetos autónomas: económica, sexual y subjetivamente. Para conseguirlo tendrán que hacer un trabajo personal.

Enseguida está dicho que las mujeres que quieran devenir sujetos tienen que salir de la indefensión y empoderarse, sino fuera que sabemos que esta es una tarea ingente. Oponerse a la dominación comporta mucho trabajo, porque, como hemos visto, ésta opera a nivel corporal procedimental. En consecuencia, al optar por la subjetividad, hay que contar con un esfuerzo permanente que consiste en una atención constante, un autoanálisis, que detecte cuanto antes los efectos de la dominación sobre una misma, porque en la medida que una sabe que operan, y los puede reconocer, tiene más posibilidades de trabajar para evitarlos. Evitar reproducir el estereotipo de género femenino construyendo el propio sentido de género personal; evitar reproducir la familia tradicional; evitar "alimentarse" de cultura oficial (películas comerciales, mass-media en general); mantenerse en un sano agnosticismo lejos de las religiones oficiales que no admiten la valía de las mujeres. Hernando (2000) ${ }^{125}$ dice que las mujeres estamos aplicando la Razón al sujeto, profundizando así en la subjetividad. Por esto muchas mujeres recurren al psicoanálisis o a las psicoterapias; porque están buscando instrumentos de de introspección y de resolución racional de estos conflictos.

Pero, a su vez, como han señalado Benjamin ${ }^{126}$ y Layton $^{127}$, esta subjetivación puede suponer una forma defensiva de autonomía, como aparece en muchas mujeres blancas heterosexuales de clase media, una autonomía marcada por una tendencia a devaluar y a repudiar los atributos tradicionalmente "femeninos" de dependencia, necesidad de apoyo, y emocionalidad. Layton, además está haciendo un esfuerzo para integrar la noción de clase social a su teorización sobre el género, la raza y la orientación sexual, y sugiere que la ideología junto con la clase son vividas como carácter narcisista, y que la mayoría somos inconscientes de ello, y tenemos puntos ciegos respecto al mantenimiento del statu quo jerárquico que nos causa dolor. Layton advierte particularmente a los/las terapeutas de estos puntos ciegos que pueden dificultar el poder hablar de ellos en el encuentro analítico.

La familia tradicional es una de las instituciones que ha sido más cuestionada, y con razón. Por eso actualmente hay tantas formas de organizarse la vida personal. Berbel $(2004)^{128}$ presenta un puñado: grupos de jóvenes de ambos sexos o del mismo que conviven; padres o madres con criaturas; separados o separadas con criaturas o sin ellas, creando nuevas agrupaciones familiares donde pueden nacer criaturas comunes; parejas del mismo o de distinto sexo

125. Hernando, A., "Factores...".

126. Benjamin, J., Lazos...

127. Layton, L., ¿Who's...

128. Berbel, S., Sin cadenas... 
viviendo juntas; casadas o no, con criaturas propias o adoptadas, o no; personas que viven solas y que tienen parejas que también viven solas, o no; pero posiblemente en la mayoría de opciones cada persona haciéndose cargo de si misma, en términos económicos, y de la parte de sus criaturas, si las hay. Actualmente la forma más común y satisfactoria de relación de pareja es la igualitaria (parentalidad dual ${ }^{129}$ o nuevo contrato sexual ${ }^{130}$ ), para esto el trabajo remunerado de ambos miembros es fundamental, porque les permite mantener la sensación de competencia por un lado, y de libertad por el otro. En esta modalidad ambos miembros de la pareja se comprometen a hacerse cargo tanto de los aspectos materiales como de los emocionales de sus criaturas y de si mismos.

En definitiva, en las actuales sociedades democráticas, los individuos, como parte del ejercicio responsable de su libertad, escogen los papeles adultos, los crean, de manera que la psicología y la psicoterapia contemporáneas han empezada a considerar la identidad de género, e incluso la orientación sexual como resultado del compromiso consciente de la persona en la construcción de aspectos particulares de su yo (Bem, 1993) ${ }^{131}$, sin negar "el misterio de la homosexualidad" (Corbett, 2002) $)^{132}$.

Dimen (2003) ${ }^{133}$ lo formula diciendo que "nuestras ideas influyen en lo que somos y son parte de nuestra subjetividad y de la vida social; por lo tanto, las ideas y sus efectos constituyen un componente objetivo de las formas de vida que vivimos. Hay algo fascinante en la manera como construimos el cuerpo, la mente, el género; o no lo hacemos. El cuerpo es el lugar de luchas complejas para la libertad y es una protección contra la dominación. Y, naturalmente, esta no puede ser, no es, una lucha completamente lograda".

O como lo dice Harris (2005) ${ }^{134}$ : "Las constricciones culturales y las lecturas corporales afectan al género de muchas maneras, pero a pesar de ello, cada persona hace un compromiso creativo, y se guarda y se da en una negociación sin fin consigo misma, con el otro/la otra y con la cultura".

129. Benjamin, J., Lazos...

130. Berbel, S., Sin cadenas...

131. Bem, S, L., The lenses...

132. Corbett, K., "The mystery of Homosexuality", en Dimen, M. y Goldner, V., Gender in Psychonalytic Space. New York: Other Press, 2002.

133. Dimen, M., Sexuality, Intimacy, Power. Hillsdale: The Analytic Press, 2003.

134. Harris, A., Gender... 